\title{
Inhibitory performance of some pyrazole derivatives against corrosion of mild steel in 1.0 M HCl: Electrochemical, MEB and theoretical studies
}

\author{
S.A. Mrani, ${ }^{1}$ S. El Arrouji, ${ }^{1}$ K. Karrouchi ${ }^{2}$ F. El Hajjaji, ${ }^{1 *}$ K.I. Alaoui, ${ }^{1}$ \\ Z. Rais ${ }^{1}$ and M. Taleb ${ }^{1}$ \\ ${ }^{1}$ Laboratoire d'Ingénierie d'Electrochimie de Modélisation et d'Environnement (LIEME) \\ FSDM Fès, Morocco \\ ${ }^{2}$ Laboratoire National de Contrôle des Médicaments, D M P. Ministère de la Santé, \\ Madinat Al Irnane, BP 6206, Rabat, Morocco \\ *E-mail: el.hajjajifadoua25@gmail.com
}

\begin{abstract}
In this study, we discussed the inhibition properties of three new Pyrazole derivatives (DPA, DPM and DPF) against the corrosion of mild steel in $1.0 \mathrm{M} \mathrm{HCl}$, using the weight loss technique, the stationary methodand the transitional method. The experimental results show that the inhibitionproperties increase with the concentration and can reach a limit value of $97 \%$ for the inhibitor DPA at $10^{-3} \mathrm{M}$. The curves of polarization show that the Pyrazole derivatives were a mixed inhibitor. The data obtained by electrochemical impedance spectroscopy were analyzed to be modeled by appropriate equivalent circuit models. The evolution of the temperature leads to a decrease in the inhibition efficiency of the Pyrazole compounds. Several adsorption isotherms have been modeled such as Langmuir, Temkin, Frumkin, Flory-Huggins, Freundlich and the kinetic thermodynamic model of El-Awady, in order to provide additional information on the inhibitory properties of the compounds studied. The coefficient of determination values of all the isotherms are very high, from the two models of Flory-Huggins and El-Awady we find that the adsorption of molecules on the surface of the steel moves more than a single molecule of water which is at odds with the Langmuir isotherm. Whereas the isotherms of Temkin and Frumkin suggest the existence of the lateral interactions between the adsorbed species. Scanning electron microscopy (SEM) and EDX analyzes were used to characterize the chemical composition of the film formed on the surface of the steel. Surface studies have shown that the inhibitory layer consists of an iron oxide/hydroxide mixture in which the N, F atoms are incorporated. The DFT studies have also been carried out for protonated form of the inhibitor molecules by considering that in acidic medium the heteroatoms of organic inhibitors easily undergo protonation. The experimental and density functional theory (DFT) studies were in good agreement.
\end{abstract}

Keywords: pyrazole, mild steel, corrosion inhibition, surface, adsorption, DFT.

Received: July 9, 2018. Published: November 8, 2018

doi: $\underline{10.17675 / 2305-6894-2018-7-4-5}$ 


\section{Introduction}

Currently, prevention against metal corrosion becomes a necessity, considering the intensive use of these metals in most industrial processes. The iron, up to stainless steels plays an important role in all industries [1-3], as well as acid solutions are heavily consumed in many industrial processes for exemple: cleaning, chemical processing and acidification of refinery oil. However, these materials could be corroded during these applications, what entrain on one hand an enormous economic loss, and others part a wasting of natural resources. Consequently, the search and the application of new effective inhibitors of corrosion become an obligation. The choice of suitable inhibitors depends especially on the structure as well as their uses in various environments. The organic inhibitors are the most effective compounds because they contain heteroatoms, such as $\mathrm{O}$, N, S and multiple connections, allowing adsorption on the metal surface [4-12]. Furthermore, the adsorption of these compounds on the metal is linked to the existence of substituents and functional groups such as the aromatic ring, the combined system $p$, the effect of mesomer, inductive and steric factors by physico-chemical interactions [13], [14].

In order to correlate the effect of the substitution with inhibitory activity, the numerous studies have been undertaken in this direction $[15,16]$. So, thanks to their anticorrosive properties, the quinolinol and its derivatives have received a remarkable attention of inhibition of the metallic corrosion during these last years[17, 18]. These compounds exhibit satisfactory inhibition properties against the corrosion of the steel in acid solutions. Previous reports [19] showed that the efficiency of inhibition of heterocycle compounds containing heteroatomincreases with the number of aromatic rings and the availability of electronegative atoms in their structure.

The pyrazole derivatives compounds are products which have given encouraging results towards the inhibition of the corrosion of several metals. El Arrouji et al. [20] studied the effect of N1,N1-bis(2-(bis((3,5-dimethyl-1H-pyrazol-1-yl)methyl)amino)ethyl)N2,N2-bis((3,5-dimethyl-1H-pyrazol-1-yl)methyl)ethane-1,2-diamine: PAP and diethyl-1,1'(((4-acetylphenyl)azanediyl)-bis(methylene))-bis(5-methyl)-1 $H$-pyrazole-3-carboxylate): PAC on the corrosion of steel in $1 \mathrm{M}$ hydrochloric acid medium in a temperature range of $25^{\circ} \mathrm{C}$ and $60^{\circ} \mathrm{C}$ by weight loss, polarization curves and spectroscopy of electrochemical impedance. Inhibitory efficiency increases with increasing of concentration and decreases with temperature. The inhibitory property is more marked with PAP than with PAC. The same authors [21] studied the inhibitory efficiency of the same molecules on the corrosion of steel in $0.5 \mathrm{M} \mathrm{H}_{2} \mathrm{SO}_{4}$. The results revealed that the inhibitory efficacy of PAP and APC increases with concentration. Inhibitor and the APC compound is the most effective. These two inhibitors exhibit a mixed inhibition character in $0.5 \mathrm{M} \mathrm{H}_{2} \mathrm{SO}_{4}$.

Zergaand et al. [22] have shown that other series of pyrazoles, $N, N$-bis[2-(3,5dimethyl-1H-pyrazol-1-yl)ethyl]butylamine (P1) and 5- $\{N, N$-bis[2-(3,5-dimethyl- $1 H$ pyrazol-1-yl)ethyl]amino \}pentanol (P2), behave as good inhibitors against corrosion of a 
C38 steel in $1.0 \mathrm{M} \mathrm{HCl}$. The substitution of the methyl group by the pentanol in the compound P2 significantly increases its inhibitory efficiency.

That is why it is interesting to study the inhibitive power of the compounds of pyrazole recently synthesized by similar procedures used to prepare their analogues described in the following references [23, 24]. The target of this study is to detect the correlation between inhibitory efficacy and substitution of the para position of benzene by methyl, fluorine and dimethylamine using experimental techniques in acidic medium such as weight loss, potentiodynamic polarization, and electrochemical impedance to obtain the inhibition efficiency. In order to better understand the mechanism of adsorption of pyrazole derivatives on mild steel, we applied SEM. The adsorption and inhibition behavior of DPA, DPM and DPF were supported by density functional theory (DFT) based quantum chemical calculations method. A significant correlation among the parameters of experimental and theoretical methods has been achieved in present study.

\section{Experimental procedure}

\subsection{Materials}

\subsubsection{Inhibitors}

2-(3,5-Dimethyl-1H-pyrazol-1-yl)- $N^{\prime}$-(4-(dimethylamino)benzylidene)acetohydrazide (DPA), 2-(3,5-dimethyl-1H-pyrazol-1-yl)- $N^{\prime}$-(4-methylbenzylidene)acetohydrazide (DPM) and 2(3,5-dimethyl-1 $H$-pyrazol-1-yl)- $N^{\prime}$-(4-fluorobenzylidene)acetohydrazide were synthesized according to an experimental procedure described previously [25], and the synthesis reaction is as follows:

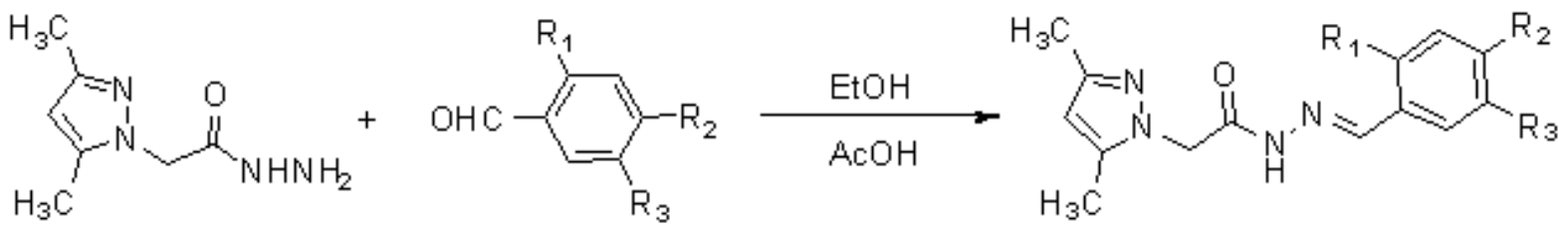

Table 1. Structures of synthesized pyrazole derivatives.

\begin{tabular}{cccccccc}
\hline Inhibitors & $\mathbf{R}_{\mathbf{1}}$ & $\mathbf{R}_{\mathbf{2}}$ & $\mathbf{R}_{\mathbf{3}}$ & $\begin{array}{c}\text { Molecular } \\
\text { Formula }\end{array}$ & Mol.Wt & M.p. $\left({ }^{\circ} \mathbf{C}\right)$ & Yields (\%) \\
\hline DPA & $\mathrm{H}$ & $\mathrm{N}\left(\mathrm{CH}_{3}\right)_{2}$ & $\mathrm{H}$ & $\mathrm{C}_{16} \mathrm{H}_{21} \mathrm{~N}_{5} \mathrm{O}$ & 299 & $212-214$ & 96 \\
DPM & $\mathrm{H}$ & $\mathrm{CH}_{3}$ & $\mathrm{H}$ & $\mathrm{C}_{14} \mathrm{H}_{18} \mathrm{~N}_{4} \mathrm{O}$ & 270 & $188-190$ & 65 \\
DPF & $\mathrm{H}$ & $\mathrm{F}$ & $\mathrm{H}$ & $\mathrm{C}_{14} \mathrm{H}_{15} \mathrm{FN}_{4} \mathrm{O}$ & 274 & $182-184$ & 94 \\
\hline
\end{tabular}

The structures of the synthesized pyrazole derivatives were analyzed and confirmed by ${ }^{1} \mathrm{H}$ NMR, ${ }^{13} \mathrm{C}$ NMR, and IR. The structures of the molecules elucidated are given in Figure 1. 


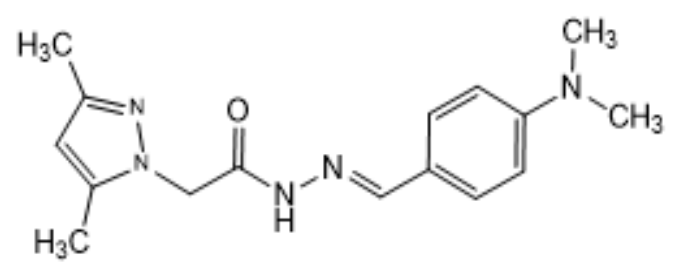

2-(3,5-dimethyl-1H-pyrazol-1-yl)- $N^{\prime}-(4-$ (dimethylamino)benzylidene)acetohydrazide

(DPA)

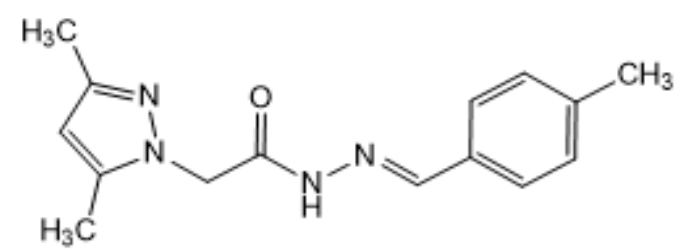

2-(3,5-dimethyl-1H-pyrazol-1-yl)- $N^{\prime}-(4-$ methylbenzylidene)acetohydrazide (DPM)

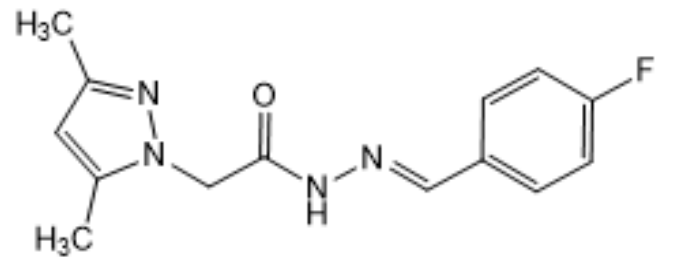

2-(3,5-dimethyl-1H-pyrazol-1-yl)- $N^{\prime}$-(4-

Fluorobenzylidene)acetohydrazide

(DPF)

Figure 1. The molecular structure of Pyrazole derivatives.

DPA: IR $\left(v\left(\mathrm{~cm}^{-1}\right)\right): 3192(\mathrm{NH}), 1675(\mathrm{C}=\mathrm{O}), 1608(\mathrm{C}=\mathrm{N}) ;{ }^{1} \mathrm{H}$ NMR: $(300 \mathrm{MHz}$, DMSO$\left.d_{6}, \delta(\mathrm{ppm})\right): 2.05\left(\mathrm{~s}, 3 \mathrm{H}, \mathrm{CH}_{3}\right), 2.12\left(\mathrm{~s}, 3 \mathrm{H}, \mathrm{CH}_{3}\right), 2.94\left(\mathrm{~s}, 6 \mathrm{H}, \mathrm{N}\left(\mathrm{CH}_{3}\right)_{2}\right), 5.13(\mathrm{~s}, 2 \mathrm{H}, \mathrm{N}-$ $\left.\underline{\mathrm{CH}}_{2}-\right), 5.79(1 \mathrm{H}, \mathrm{s}, \mathrm{CH}$-pyrazole), $6.71(\mathrm{~d}, J=9.0 \mathrm{~Hz}, 2 \mathrm{H}, \mathrm{H}-\mathrm{Ar}), 7.48(\mathrm{~d}, J=9.0 \mathrm{~Hz}, 2 \mathrm{H}$, $\mathrm{H}-\mathrm{Ar}), 8.05(1 \mathrm{H}, \mathrm{s}, \mathrm{N}=\mathrm{CH}), 11.39(\mathrm{~s}, 1 \mathrm{H}, \mathrm{NHCO}) ;{ }^{13} \mathrm{C}$ NMR: $\left(75 \mathrm{MHz}, \mathrm{DMSO}-d_{6}, \delta\right.$

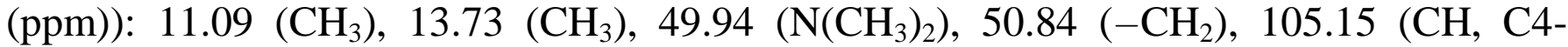
pyrazole), 112.25 (CH, C-Ar), 121.73 (C-Ar), 128.66 (CH, C-Ar), 140.53 (C, C5pyrazole), $144.25(\mathrm{CH}, \mathrm{N}=\mathrm{CH}), 144.45(\mathrm{C}, \mathrm{C} 3$-pyrazole $), 152.05\left(\mathrm{C}-\mathrm{N}\left(\mathrm{CH}_{3}\right)_{2}\right), 168.39(\mathrm{C}$, $\mathrm{C}=\mathrm{O})$. ESI-MS: $m / z=300.01[\mathrm{M}+\mathrm{H}]^{+}$.

DPM: IR $\left(v\left(\mathrm{~cm}^{-1}\right)\right): 3425(\mathrm{NH}), 1678(\mathrm{C}=\mathrm{O}), 1619(\mathrm{C}=\mathrm{N}) ;{ }^{1} \mathrm{H}$ NMR: $(300 \mathrm{MHz}$, DMSO$\left.d_{6}, \delta(\mathrm{ppm})\right): 2.05\left(\mathrm{~s}, 3 \mathrm{H}, \mathrm{CH}_{3}\right), 2.12\left(\mathrm{~s}, 3 \mathrm{H}, \mathrm{CH}_{3}\right), 2.31\left(\mathrm{~s}, 3 \mathrm{H}, \mathrm{CH}_{3}\right), 5.17(\mathrm{~s}, 2 \mathrm{H}$, $\left.\mathrm{N}-\underline{\mathrm{CH}}_{2}-\right), 5.79(1 \mathrm{H}, \mathrm{s}, \mathrm{CH}-$ pyrazole $), 7.23(\mathrm{~d}, J=7.8 \mathrm{~Hz}, 2 \mathrm{H}, \mathrm{H}-\mathrm{Ar}), 7.57$ (d, $J=7.8 \mathrm{~Hz}$, $2 \mathrm{H}, \mathrm{H}-\mathrm{Ar}), 8.16(1 \mathrm{H}, \mathrm{s}, \mathrm{N}=\mathrm{CH}), 11.52(\mathrm{~s}, 1 \mathrm{H}, \mathrm{NHCO}) ;{ }^{13} \mathrm{C}$ NMR: $\left(75 \mathrm{MHz}, \mathrm{DMSO}-d_{6}, \delta\right.$ (ppm)): $11.05\left(\mathrm{CH}_{3}\right), 13.81\left(\mathrm{CH}_{3}\right), 19.94\left(\mathrm{CH}_{3}\right), 50.95\left(-\mathrm{CH}_{2}\right), 105.45(\mathrm{CH}, \mathrm{C} 4-$ pyrazole $)$, $112.63(\mathrm{CH}, \mathrm{C}-\mathrm{Ar}), 122.73(\mathrm{CH}, \mathrm{C}-\mathrm{Ar}), 128.66(\mathrm{CH}, \mathrm{C}-\mathrm{Ar}), 140.53$ (C, C5-pyrazole), $144.75(\mathrm{C}, \mathrm{C} 3$-pyrazole $), 146.22(\mathrm{CH}, \mathrm{N}=\mathrm{CH}), 150.05\left(\mathrm{C}-\mathrm{CH}_{3}\right), 169.30(\mathrm{C}, \mathrm{C}=\mathrm{O})$. ESIMS: $m / z=271.0[\mathrm{M}+\mathrm{H}]^{+}$.

DPF: IR $\left(v\left(\mathrm{~cm}^{-1}\right)\right): 3336(\mathrm{NH}), 1677(\mathrm{C}=\mathrm{O}), 1619(\mathrm{C}=\mathrm{N}) ;{ }^{1} \mathrm{H}$ NMR: (300 MHz, DMSO$\left.d_{6}, \delta(\mathrm{ppm})\right): 2.05\left(\mathrm{~s}, 3 \mathrm{H}, \mathrm{CH}_{3}\right), 2.18\left(\mathrm{~s}, 3 \mathrm{H}, \mathrm{CH}_{3}\right), 5.18\left(\mathrm{~s}, 2 \mathrm{H}, \mathrm{N}-\underline{\mathrm{CH}}_{2}-\right), 5.80(1 \mathrm{H}, \mathrm{s}, \mathrm{CH}-$ pyrazole), $7.24(\mathrm{~d}, J=8.7 \mathrm{~Hz}, 2 \mathrm{H}, \mathrm{H}-\mathrm{Ar}), 7.78(\mathrm{~d}, J=8.7 \mathrm{~Hz}, 2 \mathrm{H}, \mathrm{H}-\mathrm{Ar}), 8.00(1 \mathrm{H}, \mathrm{s}$, $\mathrm{N}=\mathrm{CH}), 11.60(\mathrm{~s}, 1 \mathrm{H}, \mathrm{NHCO}) ;{ }^{13} \mathrm{C}$ NMR: $\left(75 \mathrm{MHz}, \mathrm{DMSO}-d_{6}, \delta(\mathrm{ppm})\right): 11.05\left(\mathrm{CH}_{3}\right)$, $13.73\left(\mathrm{CH}_{3}\right), 50.80\left(-\mathrm{CH}_{2}\right), 105.20(\mathrm{CH}, \mathrm{C} 4$-pyrazole $), 116.74(\mathrm{CH}, \mathrm{C}-\mathrm{Ar}), 129.85(\mathrm{CH}$, C-Ar), 131.05 (C-Ar), 140.54 (C, C5-pyrazole), 143.25 (C, C3-pyrazole), 146.81 (CH, $\mathrm{N}=\mathrm{CH}), 165.14(\mathrm{C}-\mathrm{Cl}), 169.05(\mathrm{C}, \mathrm{C}=\mathrm{O}) . \mathrm{ESI}-\mathrm{MS}: m / z=275.1[\mathrm{M}+\mathrm{H}]^{+}$. 


\subsubsection{Mild steel specimens}

The chemical composition of the mild steel specimens used in this study is $0.21 \% \mathrm{C}$, $0.38 \% \mathrm{Si}, 0.05 \% \mathrm{Mn}, 0.05 \% \mathrm{~S}, 0.09 \% \mathrm{P}, 0.01 \% \mathrm{Al}$, and the remainder iron $(\mathrm{Fe})$. These specimens were prepared before each test. They were abraded utilizing various grades of abrasive paper, followed by rinsing with distilled water, degreasing in ethanol and drying under an air dried.

\subsubsection{Solutions}

1.0 $\mathrm{M} \mathrm{HCl}$ was carefully prepared by dilution of analytical grade $37 \%$ hydrochloric acid with double distilled water. The range of concentrations used for the inhibitors is $10^{-6}$ to $10^{-3}$. This concentration was determined after studying the solubility of the inhibitors in the corrosive medium

\subsection{Weight loss measurements}

The gravimetric method was carried out in glass vials containing $100 \mathrm{ml}$ of solution without and with the addition of various concentrations of the inhibitor in $1 \mathrm{M} \mathrm{HCl}$ solution. The temperature of the electrolyte solutions was maintained at $298 \mathrm{~K}$ by a Thermostatted water bath. After 6 hours of immersion the specimens were collected and cleaned thoroughly and weighed at $10^{-4} \mathrm{M}$ to determine corrosion rate. The inhibition efficiency is defined as follows:

$$
\eta_{\% \mathrm{w}}=\frac{W_{0}-W}{W_{0}} \times 100
$$

Where, $W_{0}$ and $W$ are the values of corrosion weight loss after immersion in solution without and with inhibitor, respectively.

\subsection{Electrochemical techniques}

All electrochemical study was carried out by a Potentiostat Radiometer-analytical PGZ 100 and controlled with analysis software Voltamaster 4 which performed a three electrode cell. Mild steel specimen was used as working electrode, the platinum electrode which is the counter electrode and the reference electrode as the saturated electrode. The specimen was maintained at open circuit for $30 \mathrm{~min}$ and thereafter the potentiodynamic polarization curves were measured at the potential range of -700 to $-200 \mathrm{mV}$ (SCE) and scan rate of $1 \mathrm{mV} \mathrm{s}^{-1}$.

The corrosion inhibition efficiency is evaluated from the corrosion current densities values using the relationship:

$$
\eta_{\mathrm{p}}=\frac{i_{\text {corr }}^{0}-i_{\text {corr }}}{i_{\text {corr }}^{0}} \times 100
$$


Where $i_{\text {corr }}^{0}$ and $i_{\text {corr }}$ are the corrosion current densities values without and with inhibitor, respectively.

Electrochemical impedance curves were measured under the same conditions as the polarization curves using a function response analyser with small amplitude of $10 \mathrm{mV}$ over a frequency domain from $100 \mathrm{kHz}$ to $10 \mathrm{MHz}$ at $308 \mathrm{~K} .1 \mathrm{~cm}^{2}$ surface area of mild steel was exposed to the corrosive solution. The inhibiting efficiency was calculated using the following equation:

$$
\eta_{\mathrm{EIS}}=\frac{R_{\mathrm{ct}}-R_{\mathrm{ct}}^{0}}{R_{\mathrm{ct}}} \times 100
$$

Where $R_{\mathrm{ct}}^{0}$ and $R_{\mathrm{ct}}$ are the charge transfer resistance values in the absence and presence of inhibitor, respectively.

\subsection{Surface analysis}

For morphological studies, mild steel specimens was exposed into $1 \mathrm{M} \mathrm{HCl}$ solution, without and with $10^{-3} \mathrm{M}$ the organic inhibitors for duration of $6 \mathrm{~h}$. The specimens were then carried out using scanning an environmental scanning electron microscope (FEI company quanta 200).

\subsection{Computational methods}

All quantum chemistry calculations were performed using density functional theory (DFT) [26, 27], adopting hybrid functional B3LYP with Pople base 6-31 G (dp) [28] implemented in the program Gaussian 09.

\section{Results and discussions}

\subsection{Tafel polarization measurements}

The current-potential curves for mild steel in hydrochloric acid solutions were obtained in the absence and presence of various concentrations of the pyrazole compounds at $25^{\circ} \mathrm{C}$, and the curves are shown in Figure 2. These figures indicate that the cathodic curves present a wide domain of linearity meaning that the law of Tafel is verified, and that the hydrogen reduction reaction is controlled by the pure activation process. We notice that the density of current decreases for all the concentrations compared with the obtained without inhibitor. As well as the addition of the inhibitors DPA and DPF in $\mathrm{HCl} 1 \mathrm{M}$ moves the potential of corrosion towards values more electronegative for all the concentrations. On the other hand for the compound DPM the potential moves towards more electropositive values in both concentrations $10^{-3}$ and $10^{-4}$, and this may be due to the interactions between the ions $\mathrm{Cl}^{-}$and the inhibitor DPM. 

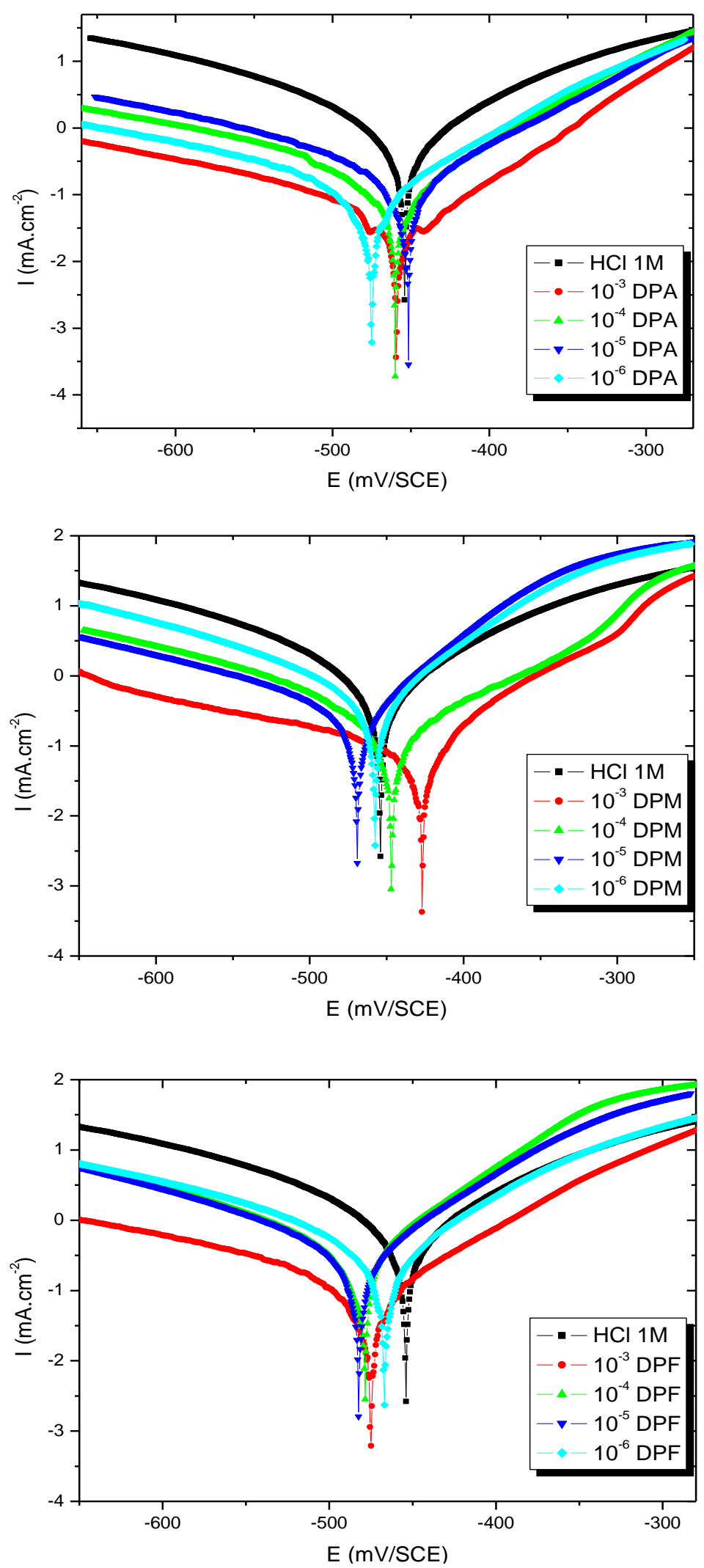

Figure 2. Potentiodynamic polarization curves for mild steel in 1M HClcontaining different concentration of DPA, DPM and DPF 
In the anodic domain we observe in absence of inhibitor an increase of the current density which accompanies the polarization of electrode, which indicates the dissolution of the ferrous ions in solution. However, in the presence of the inhibitor DPM in the concentrations $10^{-3}$ and $10^{-4}$, we observe a passivation around $-320 \mathrm{mV}$ indicating the formation of a complex protector inhibitor-Fe. This type of behavior is attributed to mixed-type inhibitors. The parameters deduced from the Tafel curves, namely: corrosion current density $\left(i_{\text {corr }}\right)$, the corrosion potential $\left(E_{\text {corr }}\right)$, the Tafel anodic slope $\left(\beta_{\mathrm{a}}\right)$ and the Tafel cathodic slope $\left(\beta_{\mathrm{c}}\right)$ are grouped in the Table 1 .

From the Table 2, we noted that the corrosion current density decreases when the inhibitors concentrations increase, attains maximum protection at $10^{-3} \mathrm{M}$. These results suggest that the pyrazole act as effective inhibitor against the corrosion of mild steel in $\mathrm{HCl}$ media. The value of $\beta_{c}$ don't change when we add the pyrazole which shows that there is no change in the process of hydrogen reduction. These results are in agreement with the structure of the inhibitors due to the presence of some active sites and hetero atoms which adsorb on the metal surface and the efficiency of its inhibitors is directly proportional to the inhibitor adsorbed. DPA is the most efficient and this is due to the presence of the dimethylamine group in the para position of benzene which leads to the increase of its electron density by the mesomeric effect. The inhibitory efficacy of the tested derivatives evolves in the following direction: DPA $>$ DPM $>$ DPF.

Table 2. Electrochemical parameters obtained from Tafel polarization curves of mild steel in $1 \mathrm{M} \mathrm{HCl}$ with and without the various concentrations of Pyrazoles compounds at $25^{\circ} \mathrm{C}$.

\begin{tabular}{|c|c|c|c|c|c|c|}
\hline Inhibitors & $\begin{array}{c}\text { Concentrations } \\
\text { (M) }\end{array}$ & $E_{\text {corr }}(\mathbf{m V})$ & 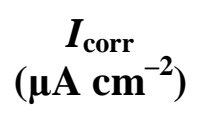 & $\begin{array}{c}\beta_{\mathrm{a}} \\
\left(\mathbf{m V} \operatorname{dec}^{-1}\right)\end{array}$ & $\begin{array}{c}\beta_{c} \\
\left(\mathbf{m V} \operatorname{dec}^{-1}\right)\end{array}$ & $\eta_{p}(\%)$ \\
\hline $\mathrm{HCl} 1 \mathrm{M}$ & - & -454 & 1.9477 & 151.8 & -182.9 & - \\
\hline \multirow{4}{*}{ DPA } & $10^{-3}$ & -459 & 0.0286 & 68.8 & -148.1 & 98 \\
\hline & $10^{-4}$ & -460 & 0.0795 & 70.3 & -90.7 & 96 \\
\hline & $10^{-5}$ & -452 & 0.0857 & 73.2 & -75.2 & 95 \\
\hline & $10^{-6}$ & -475 & 0.2058 & 98.6 & -247 & 89 \\
\hline \multirow{4}{*}{ DPM } & $10^{-3}$ & -427 & 0.1635 & 92.6 & -345.2 & 91 \\
\hline & $10^{-4}$ & -447 & 0.4071 & 98.6 & -189.2 & 79 \\
\hline & $10^{-5}$ & -469 & 0.4282 & 69.4 & -194.4 & 78 \\
\hline & $10^{-6}$ & -458 & 0.6868 & 79.3 & -151.3 & 65 \\
\hline \multirow{4}{*}{ DPF } & $10^{-3}$ & -475 & 0.2058 & 98.6 & -247.0 & 89 \\
\hline & $10^{-4}$ & -479 & 0.3142 & 62.9 & -132.4 & 84 \\
\hline & $10^{-5}$ & -482 & 0.5507 & 70.4 & -165.7 & 72 \\
\hline & $10^{-6}$ & -466 & 0.7728 & 110.8 & -200.9 & 60 \\
\hline
\end{tabular}




\subsection{Electrochemical impedance spectroscopy (EIS)}

The electrochemical impedance diagrams of mild steel in $1 \mathrm{M} \mathrm{HCl}$ in the presence of pyrazole derivatives at different concentrations are shown in Figure 3. The diagrams obtained show the existence of a single capacitive loop revealing that the process of corrosion was monitored by a single phenomenon which is the charge transfer [29]. The Nyquist plots contain a depressed imperfect semicircle, which is attributed to roughness and heterogeneity of the mild steel [30], [31].The diameter of these semicircles increase with the increase of inhibitor concentrations, which indicates the formation of a film of organic molecules caused by the interaction between the surface and the pyrazole compounds.

According to the Table 3, we note that the increase in concentration is accompanied by an increase in $R_{\mathrm{t}}$ and $\eta_{\mathrm{EIS}}(\%)$, and a decrease in $C_{\mathrm{dl}}$, which can be explained by the formation of an insoluble barrier film[23].

The results obtained by the EIS method confirm those obtained by the polarization plot, the DPA inhibitor is the most efficient in $1 \mathrm{M} \mathrm{HCl}$ and the effectiveness of the inhibitors evolves in this way: DPA > DPM > DPF.

Table 3. Fitting results of EIS for steel mild in $1 \mathrm{M} \mathrm{HCl}$ in the absence and presence of different concentrations of pyrazole derivatives at $298 \mathrm{~K}$.

\begin{tabular}{|c|c|c|c|c|c|c|c|c|}
\hline & \multirow{2}{*}{$\begin{array}{l}\text { Conc. } \\
\text { (M) }\end{array}$} & \multirow{2}{*}{$\begin{array}{c}R_{\mathrm{s}} \\
\left(\Omega \cdot \mathrm{cm}^{2}\right)\end{array}$} & \multirow{2}{*}{$\begin{array}{c}R_{\mathrm{p}} \\
\left(\Omega \cdot \mathrm{cm}^{2}\right)\end{array}$} & \multicolumn{2}{|l|}{$\mathrm{CPE}$} & \multirow{2}{*}{$\begin{array}{c}C_{\mathrm{dl}} \\
\left(\mu \mathrm{F} \cdot \mathbf{c m}^{-2}\right)\end{array}$} & \multirow{2}{*}{$\tau(\mathbf{s})$} & \multirow{2}{*}{$\eta(\%)$} \\
\hline & & & & $A\left(\mu \mathbf{F} S^{n-1} c^{-2}\right)$ & $n$ & & & \\
\hline HCl 1 M & - & 2.041 & 20.03 & 429.70 & 0.82 & 151.3 & 0.0030 & - \\
\hline \multirow{4}{*}{ DPA } & $10^{-3}$ & 2.313 & 748.1 & 58.81 & 0.78 & 24.37 & 0.01823 & 97 \\
\hline & $10^{-4}$ & 2.194 & 559.2 & 66.86 & 0.81 & 30.84 & 0.01703 & 96 \\
\hline & $10^{-5}$ & 2.245 & 440.4 & 78.84 & 0.82 & 37.64 & 0.01644 & 95 \\
\hline & $10^{-6}$ & 3.584 & 189.6 & 172.72 & 0.79 & 69.63 & 0.01322 & 89 \\
\hline \multirow{4}{*}{ DPM } & $10^{-3}$ & 6.234 & 278.7 & 169.53 & 0.74 & 58.01 & 0.01617 & 93 \\
\hline & $10^{-4}$ & 3.124 & 165.8 & 165.14 & 0.81 & 71.01 & 0.01177 & 88 \\
\hline & $10^{-5}$ & 2.687 & 90.04 & 236.80 & 0.79 & 85.14 & 0.00767 & 78 \\
\hline & $10^{-6}$ & 3.197 & 48.07 & 363.89 & 0.79 & 124.13 & 0.00597 & 58 \\
\hline \multirow{4}{*}{ DPF } & $10^{-3}$ & 3.622 & 186.7 & 157.05 & 0.81 & 68.62 & 0.01281 & 89 \\
\hline & $10^{-4}$ & 4.949 & 140.2 & 185.11 & 0.79 & 70.13 & 0.00983 & 86 \\
\hline & $10^{-5}$ & 9.75 & 119.9 & 214.22 & 0.78 & 75.45 & 0.00904 & 83 \\
\hline & $10^{-6}$ & 4.269 & 83.64 & 322.97 & 0.77 & 109.81 & 0.00918 & 76 \\
\hline
\end{tabular}



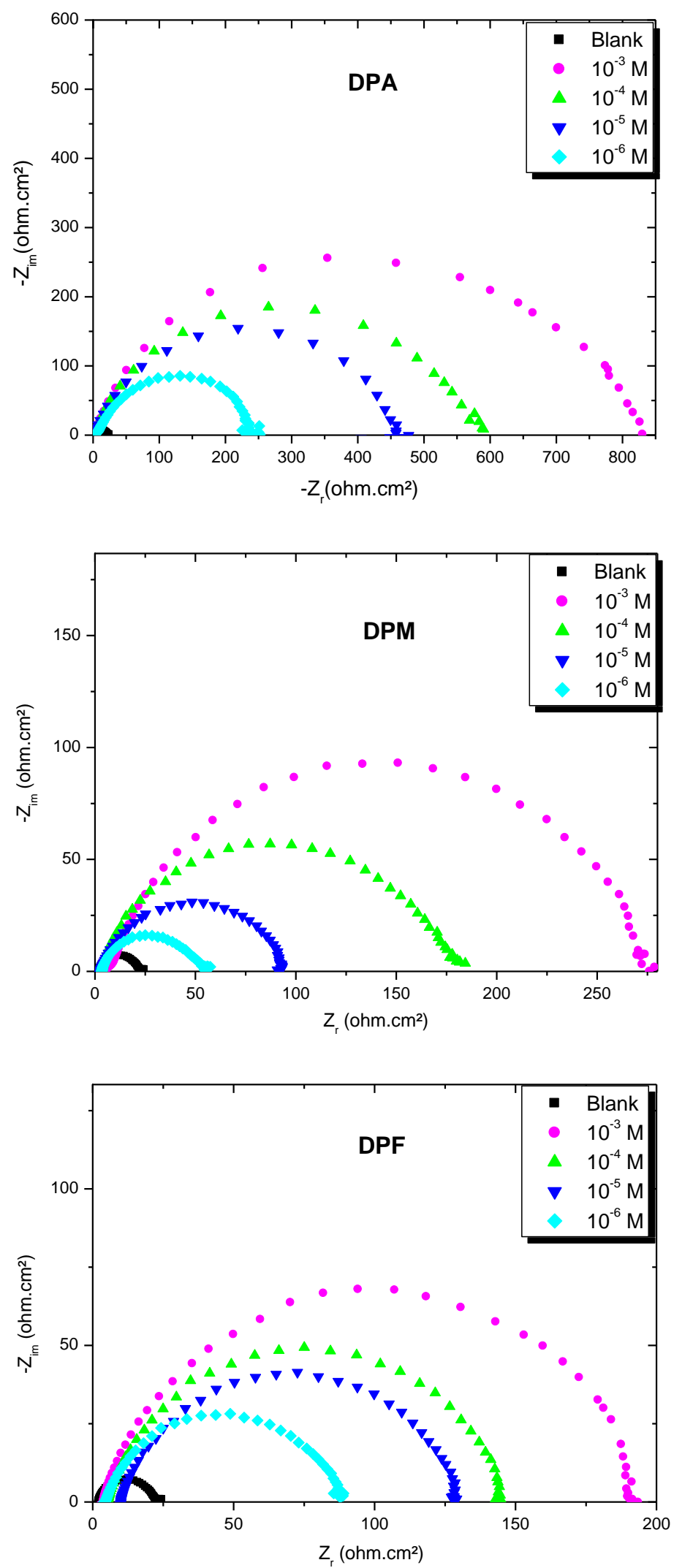

Figure 3. Nyquist plot curves for mild steel in $1 \mathrm{M} \mathrm{HCl}$ solution in presence of Pyrazole derivatives. 
On the Bode diagrams in Figure 4, we observe one capacitive time constant at the higher frequency range describes the behavior of the inhomogeneous surface layer formed at the metal solution interface (HF), corresponding to the charge transfer resistance phenomena. And a low frequency capacitive region shows the kinetic response for the charge transfer reaction [13].
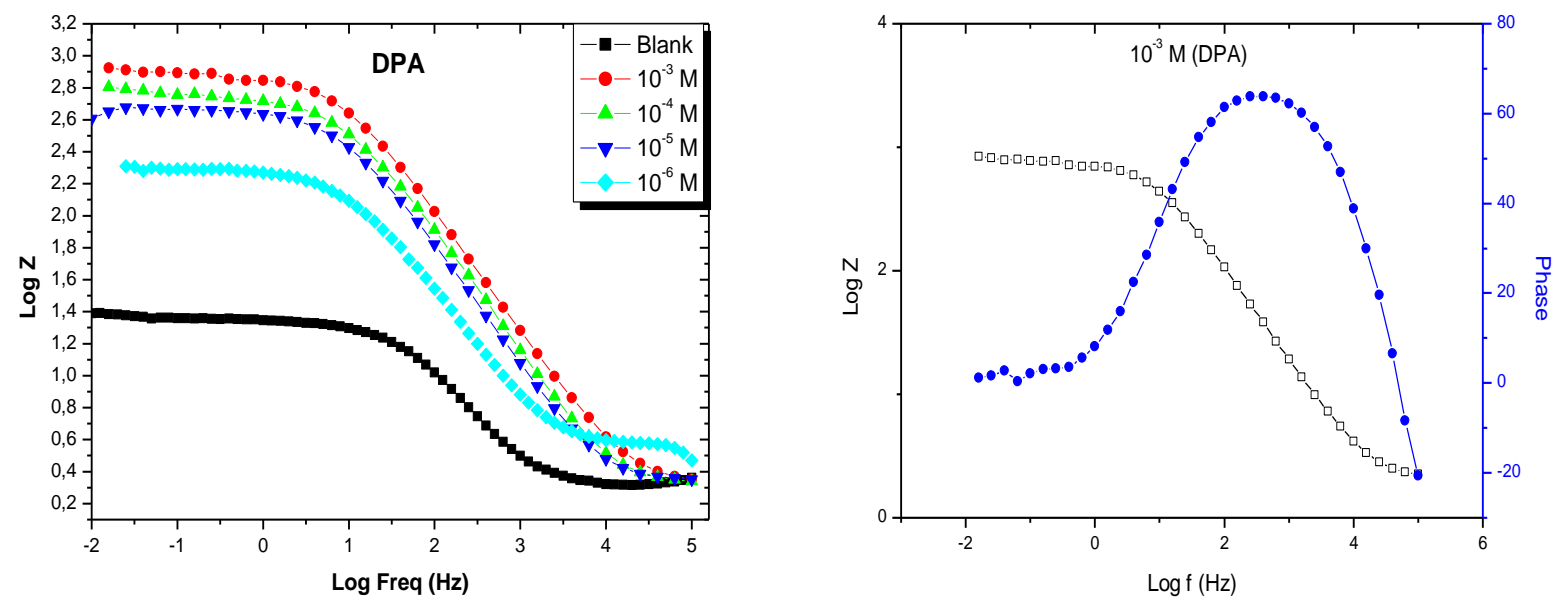

Figure 4. Bode diagrams for mild steel in $1 \mathrm{M} \mathrm{HCl}$ in presence of different concentration of DPA.
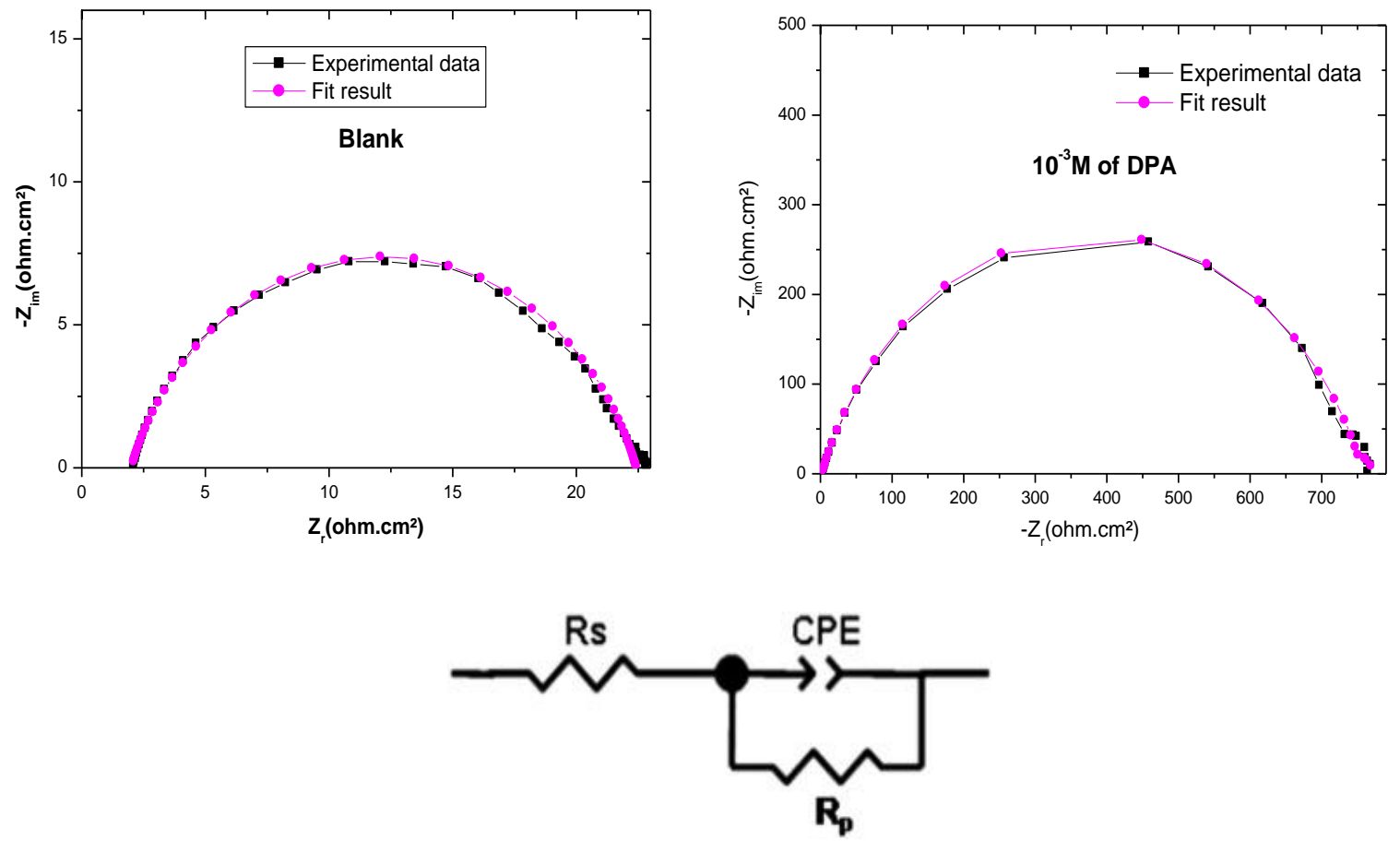

Figure 5. Electrical equivalent circuit used to fit the impedance data on the mild steel/solution interface in absence and the presence of $10^{-3}$ of DPA. 


\subsection{Effect of temperature}

The influence of temperature on the kinetics of corrosion can help to understand the mode of action of the inhibitors as well as the mechanisms involved in this corrosion. In order to determine the effect of this factor on the inhibitory power of the pyrazole compounds studied, a gravimetric study was carried out in a temperature range between $308 \mathrm{~K}$ and $338 \mathrm{~K}$ for $2 \mathrm{~h}$ at concentrations between $10^{-3} \mathrm{M}$ and $10^{-6} \mathrm{M}$. The values of the corrosion rates and the inhibitory efficiency of the studied compounds, according to the temperature, are reported in Table 3.

From Table 4, we observe that the evolution of the corrosion rate in the corrosive solution alone $1 \mathrm{M} \mathrm{HCl}$ presents a rapid and regular growth, on the other hand, the increase of the rate of corrosion in the presence of the pyrazole with the Temperature is lower than that observed in the case of the control. Thus the inhibitory efficiency and the recovery rate increases with the concentration of the inhibitors throughout the temperature range studied.

Table 4. Weight loss data for mild steel $1 \mathrm{M} \mathrm{HCl}$ without and with concentrations of Pyrazole derivative at temperature range $308-338 \mathrm{~K}$.

\begin{tabular}{ccccc}
\hline Temperatures & Inhibitors & $\begin{array}{c}\boldsymbol{W}_{\text {corr }} \\
\left(\mathbf{m g} \cdot \mathbf{c m}^{-2} \cdot \mathbf{h}^{-\mathbf{1}}\right)\end{array}$ & $\boldsymbol{E}(\boldsymbol{\%})$ & $\boldsymbol{\theta}$ \\
\hline \multirow{3}{*}{308} & blank & 0.7365 & - & - \\
& DPA & 0.0276 & 96 & 0.96 \\
& DPM & 0.1029 & 86 & 0.86 \\
& DPF & 0.1596 & 78 & 0.78 \\
\hline \multirow{3}{*}{318} & blank & 1.4713 & - & - \\
& DPA & 0.0772 & 95 & 0.95 \\
& DPM & 0.3067 & 79 & 0.79 \\
& DPF & 0.3917 & 73 & 0.73 \\
\hline \multirow{3}{*}{328} & blank & 2.6187 & - & - \\
& DPA & 0.3616 & 86 & 0.86 \\
& DPM & 0.9296 & 64 & 0.64 \\
& DPF & 0.8058 & 69 & 0.69 \\
\hline \multirow{3}{*}{338} & blank & 4.0393 & - & - \\
& DPA & 0.6693 & 83 & 0.83 \\
& DPM & 1.4826 & 63 & 0.63 \\
& DPF & 2.0157 & 50 & 0.50 \\
\hline
\end{tabular}

In general, the increase in temperature is accompanied by an increase in the corrosion rates in the presence and absence of the inhibitors, and a decrease in the inhibitory 
efficiency. In the presence of the DPA inhibitor, the inhibition efficiency values decreased slightly with increasing temperature, but the protection properties remained very good even at $338 \mathrm{~K}(83 \%)$. These results confirm that the DPA compound is considered to be the best inhibitor in the temperature range studied. The effectiveness of the DPA compound is not very sensitive to temperature, so the application of this inhibitor in the industrial field at high temperatures is promising, whereas the other inhibitors do not exhibit satisfactory efficiency in temperature increase.

\subsection{Kinetic parameters}

In order to calculate activation thermodynamic parameters of the corrosion process, Arrhenius and transition state were used [32]:

$$
\begin{gathered}
W_{\text {corr }}=A \exp \left(-\frac{E_{\mathrm{a}}}{R T}\right) \\
W_{\text {corr }}=\frac{k_{\mathrm{B}} T}{h} \exp \left(\frac{\Delta S^{*}}{R}\right) \exp \left(-\frac{\Delta H^{*}}{R T}\right)
\end{gathered}
$$

Where $E_{\mathrm{a}}$ is the apparent activation corrosion energy, $R$ is the universal gas constant, $A$ is the Arrhenius pre-exponential factor, $h$ is Plank's constant, $N$ is Avogrado's number, $\Delta S_{\mathrm{a}}$ is the entropy of activation and $\Delta H_{\mathrm{a}}$ is the enthalpy of activation.

Arrhenius plots for the corrosion rate of mild steel are given in Figure 6, the activation energies were calculated from the Arrhenius relation. The linear regression coefficient of the variation of $\ln \left(W_{\text {corr }}\right)=f(1000 / T)$ was close to 1 for the various inhibitors without and with addition of $10^{-3} \mathrm{M}$ of each compound, indicating that corrosion of the steel in $1 \mathrm{M}$ $\mathrm{HCl}$ can be elucidated using the kinetic model.
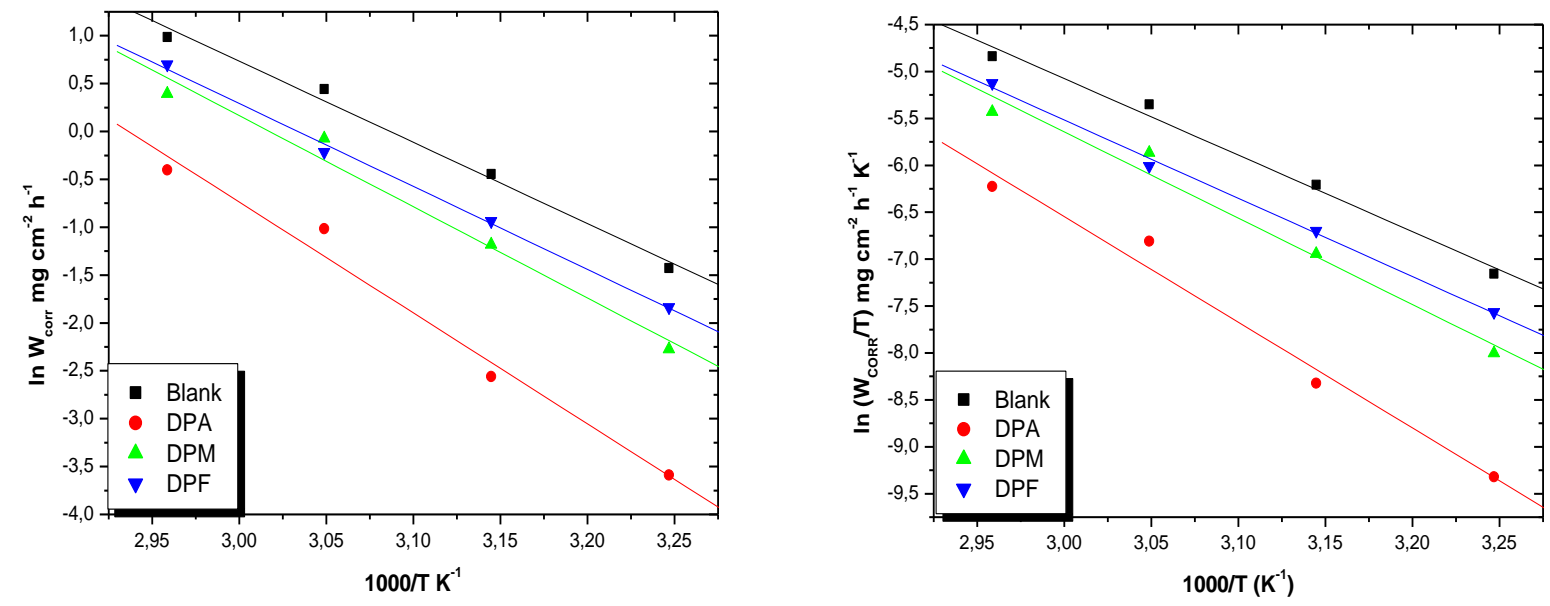

Figure 6. Arrhenius and transition state plots for the corrosion of mild steel in $1.0 \mathrm{M} \mathrm{HCl}$ in the absence and presence of various concentrations of the utilized corrosion inhibitors: DPA, DPM and DPF. 
Table 5. Kinetic and activation parameters for mild steel in $1.0 \mathrm{M} \mathrm{HCl}$ in the absence and presence of various concentrations of inhibitors.

\begin{tabular}{ccccc}
\hline Concentration $\mathbf{1 0}^{-\mathbf{3}} \mathbf{M}$ & $\boldsymbol{E}_{\mathbf{a}}\left(\mathbf{k J} \cdot \mathbf{m o l}^{\mathbf{- 1}}\right)$ & $\boldsymbol{\Delta H}_{\mathbf{a}}^{\mathbf{0}}\left(\mathbf{k J} \cdot \mathbf{m o l}^{-\mathbf{1}}\right)$ & $\boldsymbol{E}_{\mathbf{a}}-\boldsymbol{\Delta} \boldsymbol{H}_{\mathbf{a}}^{\mathbf{0}}\left(\mathbf{k J} \cdot \mathbf{m o l}^{\mathbf{- 1}}\right)$ & $\Delta \boldsymbol{S}_{\mathbf{a}}^{\mathbf{0}}\left(\mathbf{J} \cdot \mathbf{m o l}^{\mathbf{- 1}}\right)$ \\
\hline Blank & 49.27 & 46.59 & 2.67 & -95.98 \\
DPA & 96.27 & 93.59 & 2.67 & 28.91 \\
DPM & 79.12 & 76.44 & 2.67 & -15.034 \\
DPF & 72 & 69.33 & 2.67 & -35.31 \\
\hline
\end{tabular}

From the results of Table 5 we observe an increase of the $E_{\mathrm{a}}$ in the presence of $10^{-3} \mathrm{M}$ for the various inhibitors studied when compared to that in its absence, this increase can be interpreted as a process of adsorption of Physical nature means that the inhibitors adsorb onto the surface of the metal by forming electrostatic bonds [29]. Similar results have been reported by Zarrouk et al. [33], who have studied the corrosion inhibition of steel by quinoxaline derivatives in an acid medium. Tazouti et al. [34] recently discussed the inhibitory power of the new synthesized compounds. Families of quinoxaline tested as an acid corrosion inhibitor. They explained that the increase in $E_{\mathrm{a}}$ of the inhibitors studied compared to the control is attributed to the physical nature of the adsorption of its compounds on the surface of the steel.

Inspection of data in the Table 5 reveals that the values of $\Delta H_{\mathrm{a}}^{0}$ for the dissolution reaction of mild steel in $1 \mathrm{M} \mathrm{HCl}$ in the presence of the pyrazole derivatives are higher than those in its absence $46.58 \mathrm{~kJ} \cdot \mathrm{mol}^{-1}$. The value positive of $\Delta H_{\mathrm{a}}^{0}$ indicates that the dissolution reaction of steel is an endothermic dissolution process and suggests that its dissolution is slow in the presence of inhibitors [35]. These results show that the value of the activation enthalpy is more pronounced for the DPA inhibitor, which confirms its very high protection character with respect to the other compounds, and that the dissolution of the steel in the presence of this compound is difficult.

Moreover, Table 5 shows that the activation entropies obtained in the presence of the pyrazole derivatives are greater than that in its absence. The change of $\Delta S_{\mathrm{a}}^{0}$ means that there is a decrease in the disorder during the transformation of the reagents into an activated complex [36]. Negative entropy values $\Delta S_{\mathrm{a}}^{0}$ are observed for the DPP, DPM and DPF compounds, indicating the formation of a stable layer on the metal surface [37]. $\Delta S_{\mathrm{a}}^{0}$ changes sign and becomes positive in the presence of the DPA inhibitor, this reflects an increase in molecular disorder [38].

The variation of the $E_{\mathrm{a}}$ and that of the $\Delta H_{\mathrm{a}}^{0}$ vary in the same way with the concentration of inhibitor table, indicating that the corrosion process follows a reaction Unimolecular, verifying the thermodynamic relation between $E_{\mathrm{a}}$ and $\Delta H_{\mathrm{a}}^{0}$ [34]:

$$
E_{\mathrm{a}}-\Delta H_{\mathrm{a}}^{0}=R T
$$




\subsection{Thermodynamic parameters and isotherm of adsorption}

In order to determine the appropriate isotherm of the inhibitors studied, various isotherms including Langmuir, Temkin, Frumkin, Freundlich, Flory-Huggins and El-Awady were tested. According to these isotherms, the recovery rate is related to the inhibitor concentration by the following equations:

Langmuir:

$$
\frac{\theta}{1-\theta}=K_{\mathrm{ads}} C_{\mathrm{inh}}
$$

Temkin:

$$
\exp (-2 a \theta)=K_{\mathrm{ads}} C_{\text {inh }}
$$

Frumkin:

$$
\left(\frac{\theta}{1-\theta}\right) \exp (-2 a \theta)=K_{\mathrm{ads}} C_{\mathrm{inh}}
$$

Freundlich:

$$
\theta=K_{\text {ads }} C_{\text {inh }}^{1 / n}
$$

Flory-Huggins:

$$
\ln \left(\frac{\theta}{C_{\mathrm{inh}}}\right)=\ln K_{\mathrm{ads}}+a \times \ln (1-\theta)
$$

El-Awady:

$$
\left(\frac{\theta}{1-\theta}\right)^{1 / y}=K_{\mathrm{ads}} C_{\mathrm{inh}}
$$

The type of the adsorption isotherm may provide additional information regarding the inhibitory properties of the test compounds. For this, we tested several adsorption isotherms such as Langmuir, Temkin, Frumkin, Flory-Huggins, Freundlich and El-Awady isotherms. The values of the coefficients of determination are all close to unity. Which led us to deepen our research further. In fact, the values of the parameter $x$ obtained by the Flory-Huggins model are positive for the 3 inhibitors, which implies that these molecules are adsorbed on the surface of the mild steel by displacing more than one molecule of water [39]. Whereas the 1/y values of DPA, DPM and DPF obtained by the El-Awady thermodynamic/kinetic model are greater than unity, which means that these inhibitors occupy more than one active site $[40,41]$. Which is at odds with the Langmuir isotherm hypothesis which states that the adsorption of molecules on the metal surface is monolayer. The adsorption process of the DPA, DPM and DPF inhibitors also obeys the Temkin adsorption isotherm which assumes that the recovery rate varies linearly with the concentration, this variation may be related to the heterogeneity of the surface, or At lateral interactions between the adsorbed molecules [42] it can also be noted that the Frumkin isotherm takes into account the lateral interactions between the adsorbed species. The negative sign of the parameter " $a$ " of intermolecular interaction in the adsorption layer of the Temkin isotherm, as well as the negative value of the parameter " $a$ " of interaction between the molecules adsorbed on the surface of the steel of Frumkin isotherm, suggest that these side interactions in the adsorbed layer are highly repulsive. Whereas the value of $n$ obtained from the Freundlich isotherm is less than 1 which suggests that the adsorption is weak. 


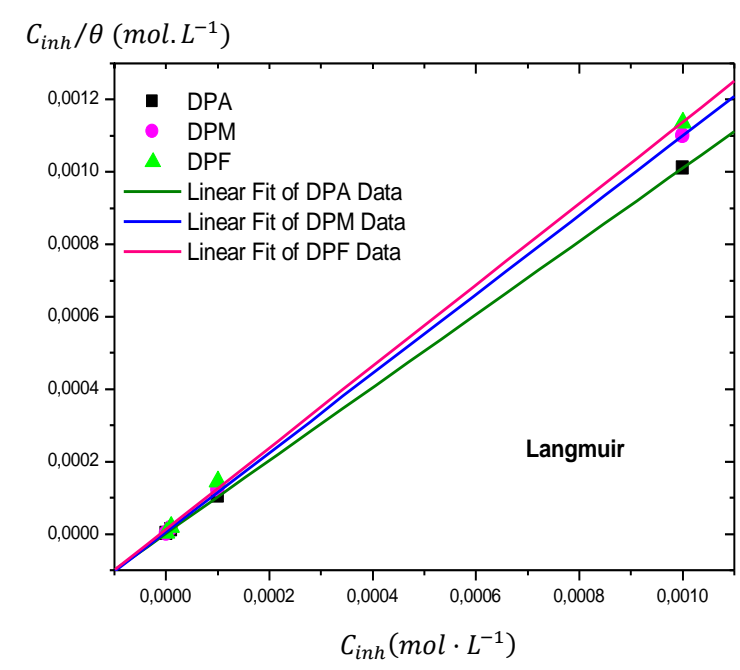

$\ln \left(C_{i n h}(1-\theta / \theta)\right)$

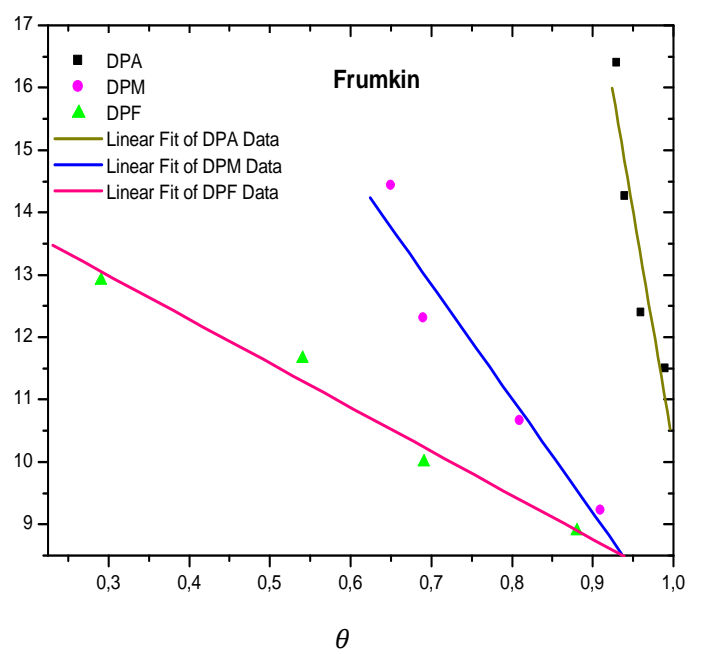

$\left.\log \left(\theta / C_{i n h}\right) \mathrm{mol} \cdot \mathrm{L}^{-1}\right)$

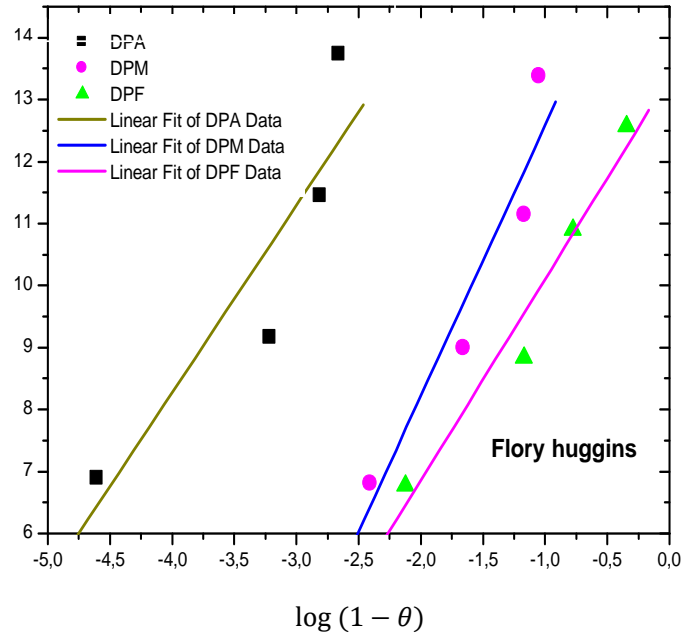

$\theta$

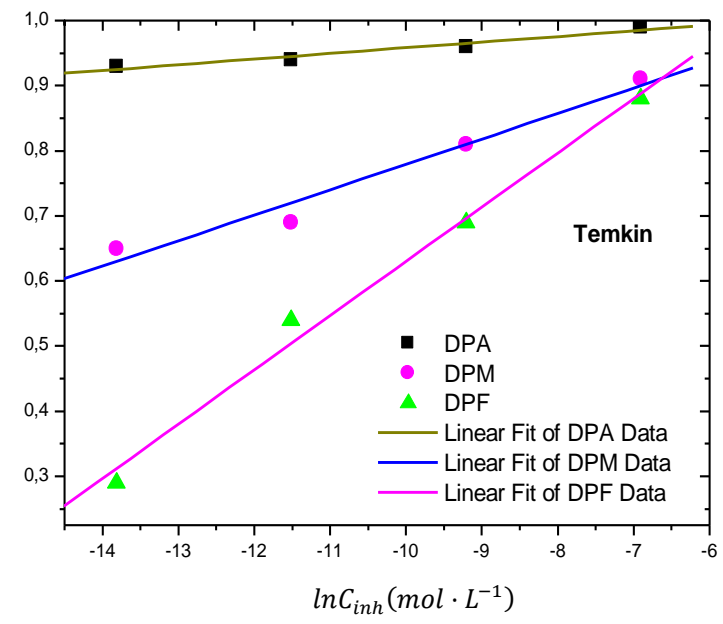

$\ln \theta$

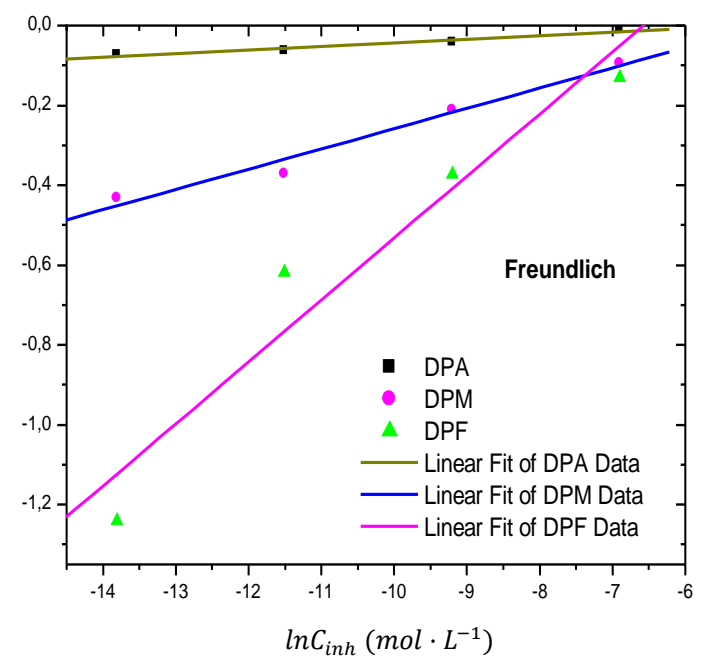

$\log (1-\theta)$

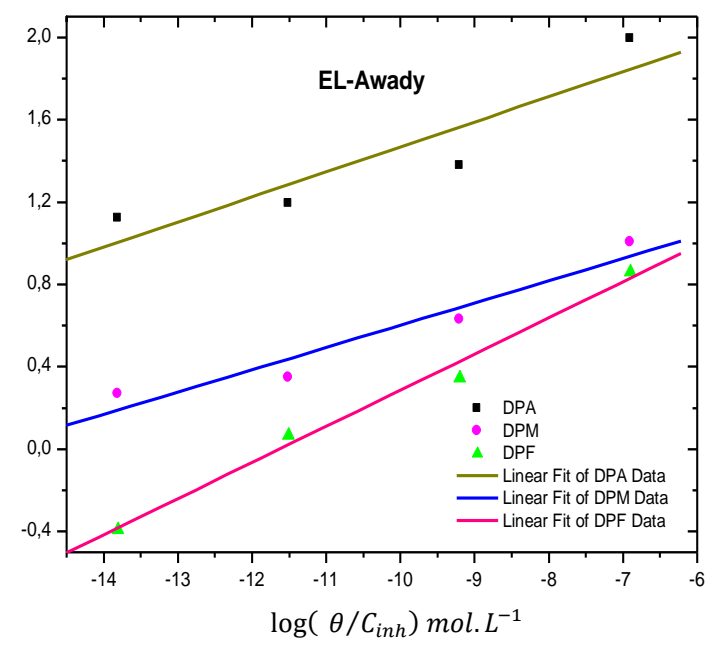

Figure 7. Different isotherm of adsorption for the corrosion of mild steel in $1.0 \mathrm{M} \mathrm{HCl}$ in the presence of $10^{-3} \mathrm{M}$ of DPA, DPM and DPF at $308 \mathrm{~K}$. 
Table 6. Adsorption parameters deduced from different adsorption isotherms for mild steel in the presence of $10^{-3} \mathrm{M}$ of DPA, DPM and DPF at $308 \mathrm{~K}$.

\begin{tabular}{|c|c|c|c|c|c|c|}
\hline Isotherm & Inhibitors & $R^{2}$ & $K_{\text {ads }}$ & $\Delta G_{\text {ads }}^{0}\left(\mathrm{~kJ} \cdot \mathrm{mol}^{-1}\right)$ & \multicolumn{2}{|c|}{ Isotherm property } \\
\hline \multirow{3}{*}{ Langmuir } & DPA & 1 & $8.16 \cdot 10^{5}$ & -45.10 & \multirow{3}{*}{ Slope } & 1.01 \\
\hline & DPM & 0.99994 & $1.74 \cdot 10^{5}$ & -41.20 & & 1.09 \\
\hline & DPF & 0.9997 & $7.46 \cdot 10^{4}$ & -39.00 & & 1.24 \\
\hline \multirow{3}{*}{ Temkin } & DPA & 0.9759 & $1.68 \cdot 10^{52}$ & -318.22 & \multirow{3}{*}{$a$} & -57.54 \\
\hline & DPM & 0.98315 & $9.97 \cdot 10^{12}$ & -86.93 & & -12.79 \\
\hline & DPF & 0.99494 & $4.22 \cdot 10^{7}$ & -55.25 & & -5.99 \\
\hline \multirow{3}{*}{ Fumkin } & DPA & 0.92504 & $2.63 \cdot 10^{37}$ & -230.93 & \multirow{3}{*}{$a$} & -37.97 \\
\hline & DPM & 0.96475 & $1.38 \cdot 10^{11}$ & -75.98 & & -9.15 \\
\hline & DPF & 0.98866 & $3.63 \cdot 10^{6}$ & -48.97 & & -3.52 \\
\hline \multirow{3}{*}{ Freundlich } & DPA & 0.97762 & 1.05 & -10.40 & \multirow{3}{*}{$n$} & 0.009 \\
\hline & DPM & 0.98676 & 1.28 & -10.92 & & 0.051 \\
\hline & DPF & 0.96809 & 2.77 & -12.89 & & 0.155 \\
\hline \multirow{3}{*}{$\begin{array}{l}\text { Flory- } \\
\text { Huggins }\end{array}$} & DPA & 0.90890 & $2.30 \cdot 10^{8}$ & -59.59 & \multirow{3}{*}{$x$} & 3.02 \\
\hline & DPM & 0.95392 & $5.27 \cdot 10^{6}$ & -49.92 & & 4.37 \\
\hline & DPF & 0.98083 & $1.95 \cdot 10^{5}$ & -41.47 & & 3.25 \\
\hline \multirow{3}{*}{ El-Awady } & DPA & 0.91245 & $1.15 \cdot 10^{22}$ & -140.00 & \multirow{3}{*}{$1 / y$} & 8.22 \\
\hline & DPM & 0.96546 & $3.68 \cdot 10^{15}$ & -102.00 & & 9.25 \\
\hline & DPF & 0.99410 & $4.31 \cdot 10^{11}$ & -78.90 & & 5.69 \\
\hline
\end{tabular}

The high and negative values of $\Delta G_{\text {ads }}^{0}$ suggests that the adsorption processof DPA, DPM and DPF inhibitors on the surface of steel is strongly favored and spontaneous in acidic medium. Bransoi et al. [43] have estimated that for values of $\Delta G_{\text {ads }}^{0}$ close to $-20 \mathrm{~kJ} \cdot \mathrm{mol}^{-1}$, there is electrostatic interaction between the charged molecules and the metal (physical adsorption), but for values close to $-40 \mathrm{~kJ} \cdot \mathrm{mol}^{-1}$ implies electron sharing or transfer between the inhibitor molecules and the surface of the metal, this is a chemisorption $[41,42]$.

\section{Scanning electron microscopy}

The morphologies of the surface and their EDX spectra corresponding to the various mild steel samples were studied in order to better understand the adsorption process that took place during the corrosion inhibition and the results obtained are presented in Figure 8. 

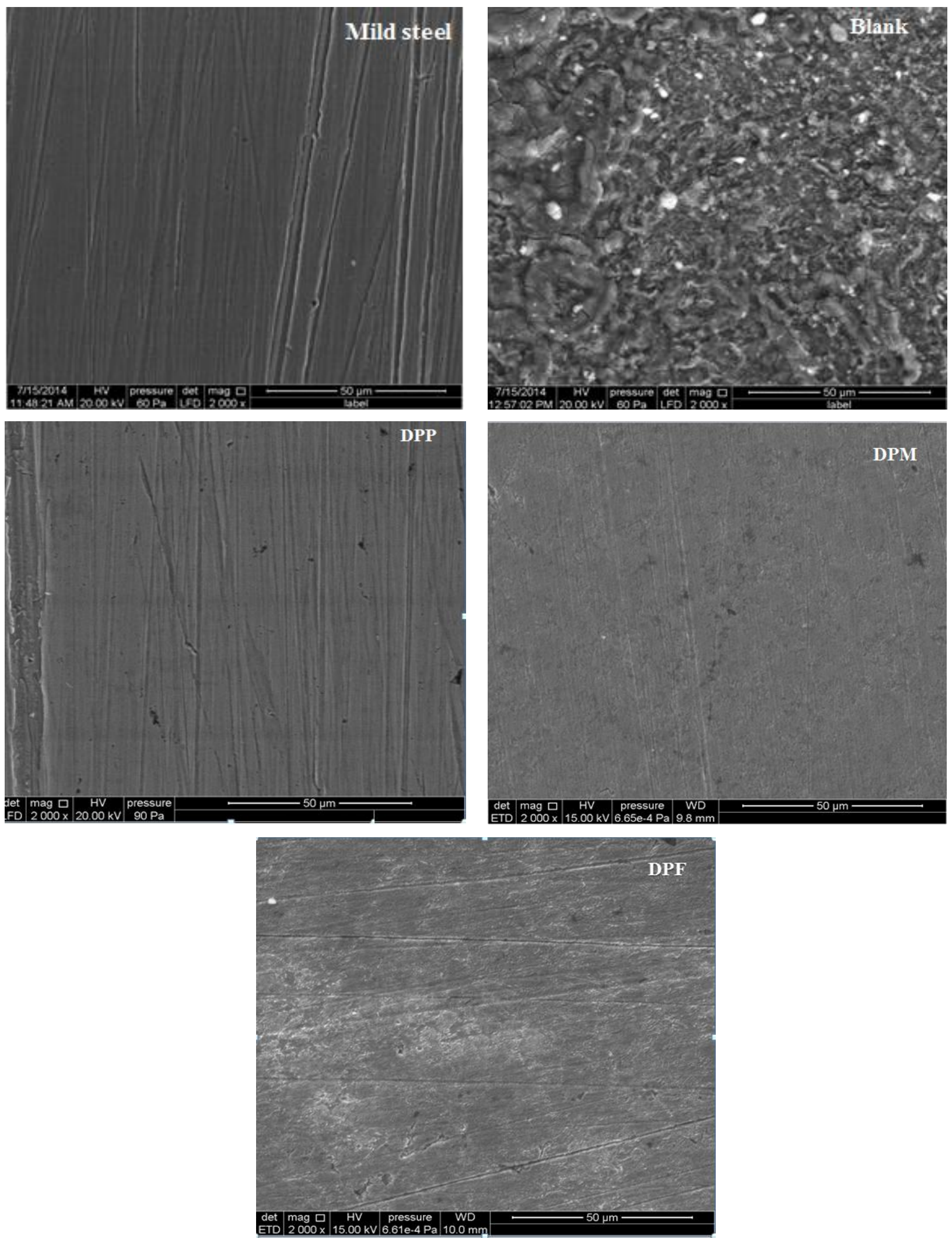

Figure 8. SEM micrographs of the mild steel surface: Metallic surface after being polished, metallic surface after $6 \mathrm{~h}$ immersion in $1 \mathrm{M} \mathrm{HCl}$ and metallic surface after $6 \mathrm{~h}$ immersion in $1 \mathrm{M} \mathrm{HCl}$ with $10^{-3} \mathrm{M}$ of DPA, DPM and DPF. 

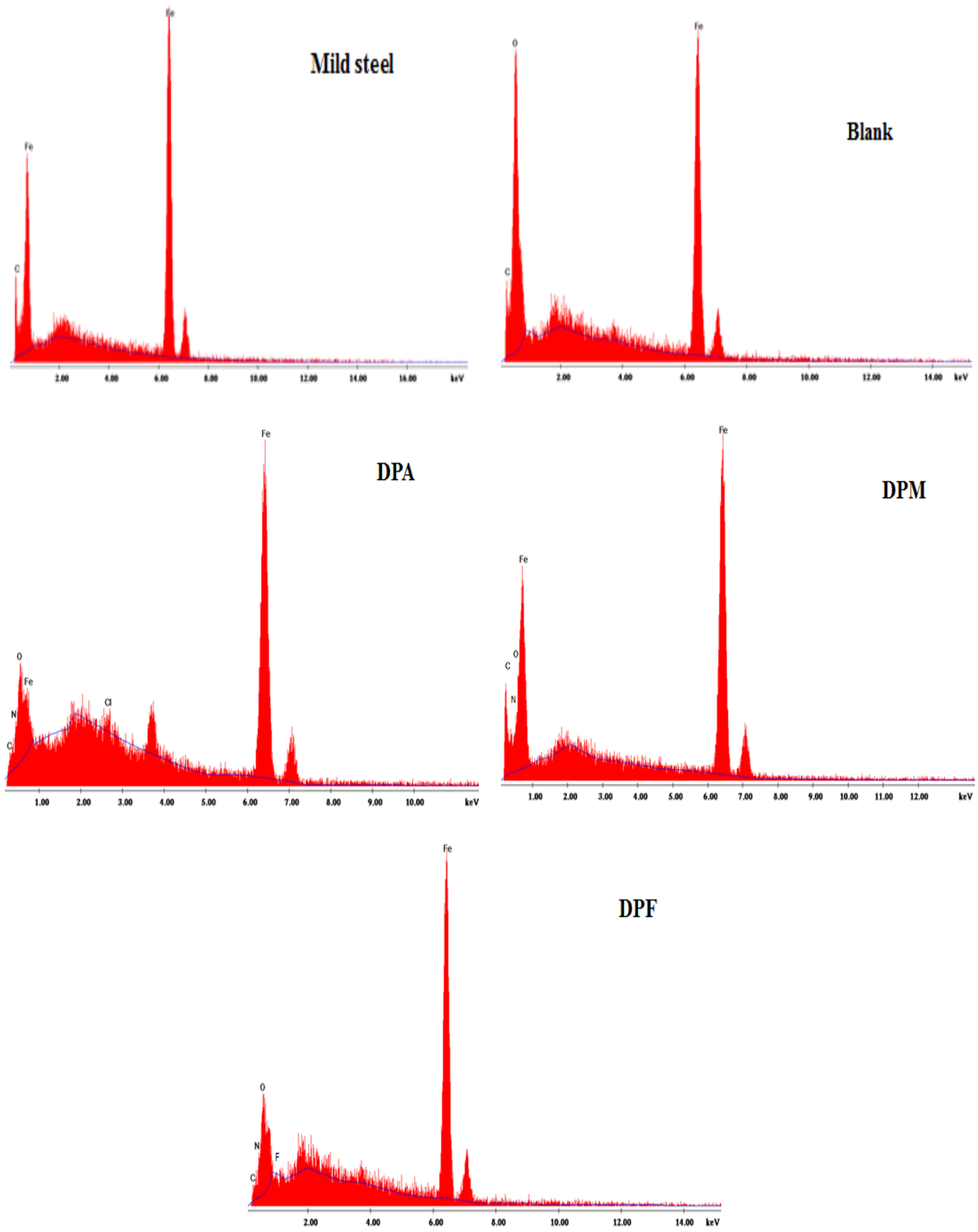

Figure 9. EDX micrographs of the mild steel surface: Metallic surface after being polished, metallic surface after $6 \mathrm{~h}$ immersion in $1 \mathrm{M} \mathrm{HCl}$ and metallic surface after $6 \mathrm{~h}$ immersion in $1 \mathrm{M} \mathrm{HCl}$ with $10^{-3} \mathrm{M}$ of DPA, DPM and DPF. 
Table 7. Chemical composition of mild steel, mild steel immersed in $1 \mathrm{M} \mathrm{HCl}$, and mild steel immersed in $1 \mathrm{M} \mathrm{HCl}$ in the presence of $10^{-3} \mathrm{M}$ DPA, DPM and DPF.

\begin{tabular}{ccccccc}
\hline $\begin{array}{c}\text { Chemical } \\
\text { composition (\%) }\end{array}$ & Fe & C & O & N & Cl & F \\
\hline Mild steel & 83.53 & 16.47 & - & - & - & - \\
Blank & 67.98 & 13.81 & 18.21 & - & - & - \\
DPA & 84.22 & 5.95 & 3.18 & 6.65 & - & - \\
DPM & 75.36 & 19.90 & 2.57 & 2.17 & - & - \\
DPF & 82.13 & 6.29 & 4.09 & 5.86 & - & 1.63 \\
\hline
\end{tabular}

We notice that the image of the surface of the steel has some scratches that could be due to abrasive paper abrasion. Nevertheless, after $6 \mathrm{~h}$ immersion at $298 \mathrm{~K}$ in $1 \mathrm{M} \mathrm{HCl}$, we observed that the surface is attacked. This shows that the latter has been corroded, whereas in the presence of $10^{-3} \mathrm{M}$ of different inhibitors, we observe that the surface of the mild steel is protected against corrosion, this is confirmed by the EDX spectra as well as the chemical composition of the layer formed on the metallic surface Table 7 .

Table 6 also shows that in the presence of inhibitors there is the formation of a protective layer which contains nitrogen, oxygen, carbon and iron. On the other hand, in the case of mild steel immersed in $1 \mathrm{M} \mathrm{HCl}$, we have reported the presence of oxygen which is due to the oxidation of the surface and the presence of chlorine which is bound to the hydrochloric acid solution.

\section{Computational studies}

The molecule with $\mathrm{N}, \mathrm{O}, \mathrm{S}$ heteroatoms appear to have a higher protonation propensity in the acidic medium. For this reason, it is necessary to examine the molecular behavior of inhibitory molecules in protonated form. However, it is advisable to make an appropriate selection of the most favorable site where protonation will occur easily. Indeed, the potential electrostatic structures can be considered as a visual method to determine the reactive centers of the molecules. The different values of the electrostatic potential are represented using different colors and the red colors representing the region of the most negative electrostatic potential. As shown by the electrostatic potential structures shown in Figure 10, neutral inhibitors, the most active center for protonation for the studied molecules is on the oxygen atom because the red color has intensified in this region.

In this study, the most favorable protonation site was selected by optimizing the geometry to the number of desirable sites where protonation is possible. The most favorable protonation site is therefore determined from the energies of the protonation values [46]. At a particular donor site, the protonation reaction in the neutral molecule (B) is written as follows:

$$
\mathrm{B}+\mathrm{H}^{+} \longrightarrow \mathrm{BH}^{+}
$$




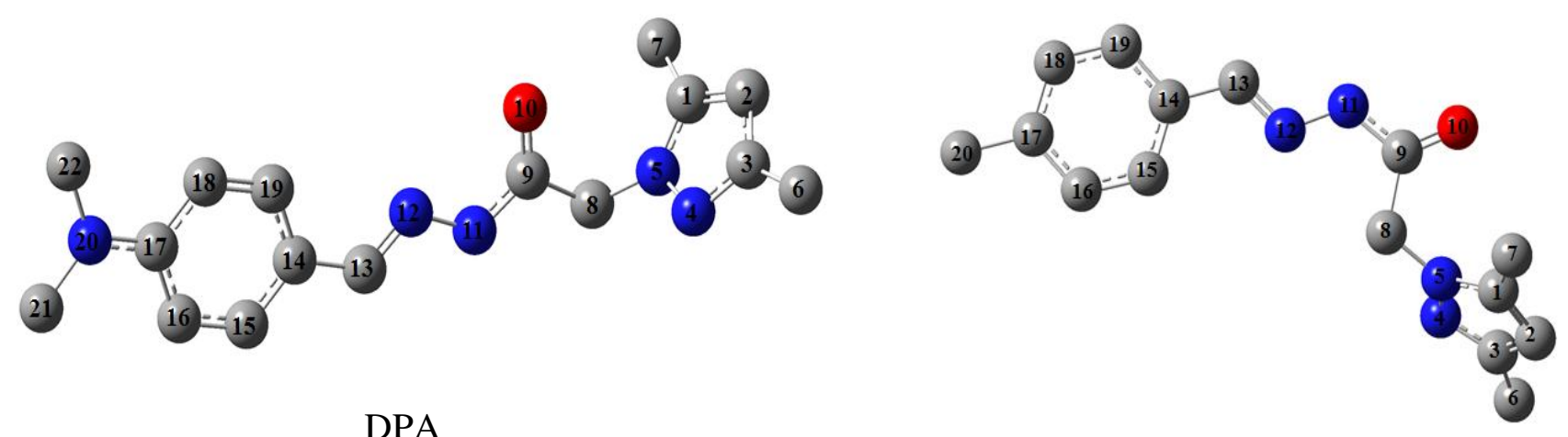

DPA

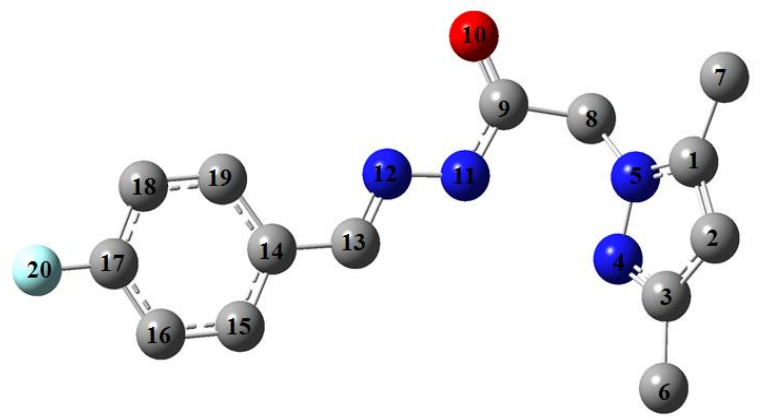

DPM

DPF

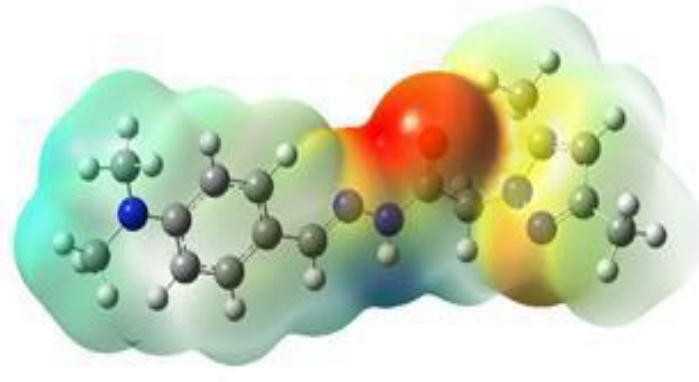

DPA

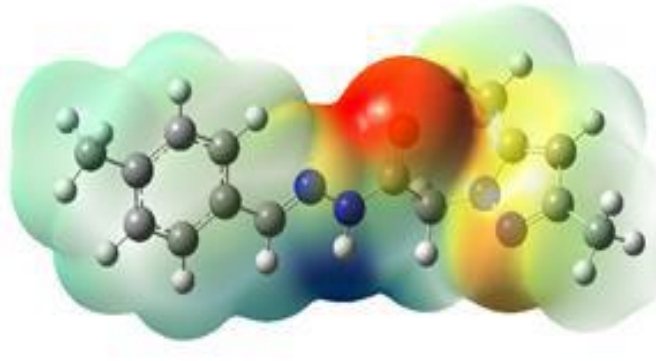

DPM

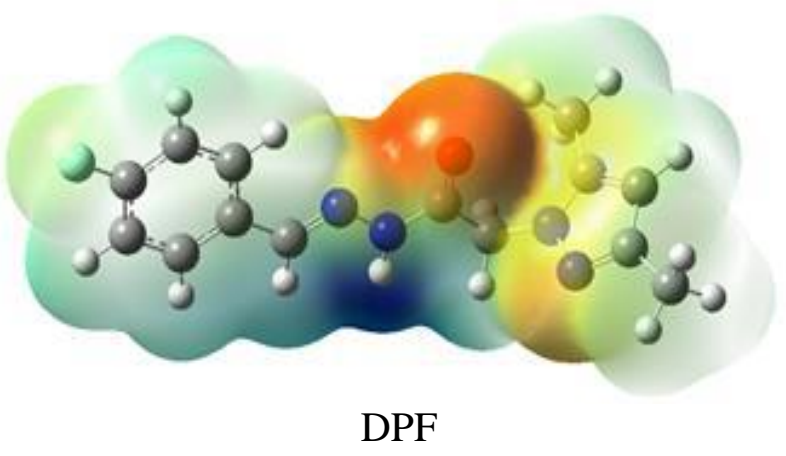

Figure 10. Distribution of protonation sites for DPA, DPM and DPF inhibitors. 
The protonation energies at a particular donor site are calculated according to the following equation:

$$
\begin{gathered}
E_{\mathrm{pro}}=E\left(\mathrm{BH}^{+}\right)-E(\mathrm{~B})-E\left(\mathrm{H}^{+}\right) \\
E\left(\mathrm{H}^{+}\right)=E\left(\mathrm{H}_{3} \mathrm{O}^{+}\right)-E\left(\mathrm{H}_{2} \mathrm{O}\right)
\end{gathered}
$$

Where $E$ is the energy obtained from the DFT output. The difference in energy between the energy of $\mathrm{H}_{3} \mathrm{O}^{+}\left(-76.4232408728\right.$ a.u.) and $\mathrm{H}_{2} \mathrm{O}(-76.0209107822$ a.u.) gives the energy of the proton in the aqueous phase [46].

There are different sites of protonation in these molecules. Protonation at the N5 and $\mathrm{N} 4$ sites (nitrogen atoms in the five-membered ring), $\mathrm{N} 20$ (nitrogen atom of the $\mathrm{NH}_{2}$ group), N11 and N12 (nitrogen atoms in the aliphatic chain), and O10 (atom of oxygen of the $\mathrm{OH}$ group) are possible. All these forms are optimized in aqueous phase.

Table 8. Calculated energy of protonation $E_{\text {pro }}$ for studied pyrazole derivatives.

\begin{tabular}{ccccccc}
\hline $\boldsymbol{E}_{\text {pro }}$ & $\mathbf{N 4}$ & $\mathbf{N 5}$ & $\mathbf{0 1 0}$ & $\mathbf{N 1 1}$ & $\mathbf{N 1 2}$ & $\mathbf{N 2 0}$ \\
\hline$E_{\text {pro }}(\mathrm{DPA})$ & -0.052253 & -0.050069 & -0.249931 & -0.044888 & -0.044885 & -0.042805 \\
$E_{\text {pro }}(\mathrm{DPM})$ & -0.051191 & -0.059785 & -0.034552 & -0.529825 & -0.033939 & \\
$E_{\text {pro }}(\mathrm{DPF})$ & -0.051012 & -0.585264 & -0.033680 & -0.477407 & -0.034478 & \\
\hline
\end{tabular}

The calculated energies of the protonation are now presented in Table 8 and we observe that the O10 atoms in DPA, N11 in the DPM, and N5 in the DPF inhibitors possess the protonation energy. The lowest in an aqueous medium compared to other atoms in the same inhibitors. This means that protonation will easily occur on these molecule sites.

Table 9. Quantitative chemical descriptors of studied proton inhibitors calculated at the B3LYP/6-

\begin{tabular}{|c|c|c|c|c|c|c|}
\hline Inhibitors & $E_{\mathrm{T}}$ (a.u.) & $E_{\text {номо }}(\mathrm{eV})$ & \multicolumn{2}{|c|}{$E_{\text {LUMO }}(\mathrm{eV})$} & $\Delta E(\mathrm{eV})$ & $\mu(\mathrm{D})$ \\
\hline DPA & -971.9969 & -5.7773 & \multicolumn{2}{|c|}{-2.7390} & 3.0383 & 93.3205 \\
\hline DPM & -877.12330 & -6.5416 & \multicolumn{2}{|c|}{-3.0736} & 3.4680 & 63.7432 \\
\hline DPF & -937.4773 & -7.5262 & \multicolumn{2}{|c|}{-3.3592} & 4.1670 & 62.8316 \\
\hline Inhibitors & $I(\mathrm{eV})$ & $A(\mathrm{eV})$ & $\chi(\mathrm{eV})$ & $\eta(\mathrm{eV})$ & $\sigma(\mathrm{eV})$ & $\Delta N$ \\
\hline DPA & 5.7773 & 2.7390 & 4.2581 & 1.5191 & 0.6583 & 0.9025 \\
\hline DPM & 6.5416 & 3.0736 & 4.8076 & 1.7340 & 0.5767 & 06322 \\
\hline DPF & 7.5262 & 3.3592 & 5.4427 & 2.0835 & 0.4799 & 0.3737 \\
\hline
\end{tabular}
$31 \mathrm{G}(\mathrm{d}, \mathrm{p})$ level. 
The analysis of the frontier orbitals energies of DPA, DPM and DPF shown in the Table 9 indicates that the substitution of the para position of the aromatic ring by the dimethylamine (DPA) leads to an increase of the $E_{\mathrm{HOMO}}$. This result is due to the presence of free doublet in dimethylamine which facilitates its adsorption on the metal surface. Moreover, the value of pyrazole derivatives show that the DPA inhibitor has the smallest energy gap (3.0383 eV) compared to those obtained for the other molecules; which gives a better reactivity to the compound DPA, thus confirming its availability to yield and accept electrons. Similarly, the dipole moment values presented in the Table 9 show that the DPA compound has the highest value, and provides information on the polarity of the molecule. This value increases the molecular reactivity of the DPA and leads to a strong adsorption on the surface of mild steel compared to other inhibitors.

Since the electronegativity $\chi$ indicates the ability of a molecule to accept electrons, the values presented in the Table 9 show that the DPA has the lowest value of $\chi$ (4.2581), probably due to the presence of the free doublet in the dimethylamine group which increases the donor effect of this molecule and therefore decreases its electronegativity.

The global descriptors are in good agreement with the experimental results, and confirm that the DPA is the best inhibitor among the three inhibitors studied.

\section{Conclusion}

From the study carried out on mild steel in $1.0 \mathrm{M} \mathrm{HCl}$ in the presence of pyrazole derivatives, we could deduce the following results:

- The molecules examined are excellent corrosion inhibitors for mild steel in a $1 \mathrm{M} \mathrm{HCl}$ solution at low concentration. DPA gives $96 \%$ higher inhibition efficiency than the other inhibitors studied under the same conditions, and this behavior is due to the presence of the $\mathrm{N}$ and $\mathrm{O}$ heteroatoms which favor its adsorption on the surface of the steel and consequently improve its efficiency.

- The results obtained by the gravimetric and electrochemical methods are in good agreement and the inhibitory power of the suspended compounds evolves in the following direction: DPA > DPM > DPF.

- The polarization curves indicate that the inhibitors studied inhibit both the anodic dissolution of the metal and the evolutionary reactions of cathodic hydrogen.

- The electrochemical impedance results show that the obtained Nyquist diagrams show a single capacitive loop, indicating that the corrosion of the mild steel is essentially controlled by the charge transfer process, leading to the formation of a protective film on the metal surface that limits the corrosion of steel.

- The study of the influence of the temperature on the inhibitory efficiency shows that it decreases with the increase of the temperature. This confirms that the adsorption of Pyrazoles on the surface of the steel is through an adsorption intermediate between physisorption and chemisorption. 
- Flory-Huggins and El-Awady's model assume that inhibiting molecules adsorb to the surface of the steel by displacing more than one molecule of water.

- The negative sign of interaction coefficient "a" of the Temkin and Frumkin adsorption isotherm suggests that the lateral interaction in the adsorbed layer is highly repulsive.

- DFT studies carried out for protonated forms of DPA, DPM and DPF provide good support the experimental results and it established that DPA interact more strongly with the metallic surface.

\section{References}

1. K. Mallaiya, R. Subramaniam, S.S. Srikandan, S. Gowri, N. Rajasekaran and A. Selvaraj, Electrochemical characterization of the protective film formed by the unsymmetrical Schiff's base on the mild steel surface in acid media, Electrochim. Acta, 2011, 56, no. 11, 3857-3863. doi: 10.1016/j.electacta.2011.02.036

2. N.A. Negm, N.G. Kandile, E.A. Badr and M.A. Mohammed, Gravimetric and electrochemical evaluation of environmentally friendly nonionic corrosion inhibitors for carbon steel in $1 \mathrm{M} \mathrm{HCl}$, Corros. Sci., 2012, 65, 94-103. doi: 10.1016/j.corsci. 2012.08.002

3. B.-Y.Liu, Z. Liu, G.-C. Han and Y.-H. Li, Corrosion inhibition and adsorption behavior of 2-((dehydroabietylamine)methyl)-6-methoxyphenol on mild steel surface in seawater, Thin Solid Films, 2011, 519, no. 22, 7836-7844. doi: 10.1016/j.tsf.2011. $\underline{06.002}$

4. F. El-Hajjaji, R.A. Belkhmima, B. Zerga, M. Sfaira, M. Taleb and M. Ebn Touhami, Time and Temperature Elucidation on Steel Corrosion Inhibition by 3-methyl-1-prop2-ynylquinoxalin-2(1H)-one in Molar Hydrochloric Acid: Part 2," J. Mater. Environ. Sci., 2014, 5, no. 1, pp. 263-270.

5. F. El-Hajjaji, M.E. Belghiti, B. Hammouti, S. Jodeh, O. Hamed, H. Lgaz and R. Salghi, Port. Electrochim. Acta, 2018, 36, 197-212. doi: 10.4152/pea.201803197

6. R. Salim, A. Elaatiaoui, N. Benchat, Z. Rais and H. Oudda, Corrosion behavior of a smart inhibitor in hydrochloric Acid molar: Experimental and theoretical studies, $J$. Mater. Environ. Sci., 2017, 8, no. 10, 3747-3758.

7. F. El-hajjaji, M. Messali, A. Aljuhani, M.R. Aouad, B. Hammouti and M.E. Belghiti, Pyridazinium-based ionic liquids as novel and green corrosion inhibitors of carbon steel in acid medium : Electrochemical and molecular dynamics simulation studies, $J$. Mol. Liq., 2018, 249, 997-1008. doi: 10.1016/j.molliq.2017.11.111

8. A. Nahle, F. El-Hajjaji, A. Ghazoui, N.-E. Benchat, M. Taleb, R. Saddik, A. Elaatiaoui, M. Koudad and B. Hammouti, Effect of substituted methyl group by phenyl group in pyridazine ring on the corrosion inhibition of mild steel in $1.0 \mathrm{M} \mathrm{HCl}$, Anti-Corros. Meth. Mater., 2018, 65, no. 1, 87-96. doi: 10.1108/ACMM-03-2017-1769

9. A. Ghazoui, N. Benchat, F. El-Hajjaji, M. Taleb, Z. Rais, R. Saddik, A. Elaatiaoui and B. Hammouti, J. Alloys Compd., 2016, 693, 510-517. doi: 10.1016/j.jallcom. $\underline{2016.09 .191}$ 
10. R. Solmaz, Investigation of adsorption and corrosion inhibition of mild steel in hydrochloric acid solution by 5-(4-Dimethylaminobenzylidene)rhodanine, Corros. Sci., 2014, 79, 169-176. doi: 10.1016/j.corsci.2013.11.001

11. A. Bouoidina, F. El-Hajjaji, M. Drissi, M. Taleb, B. Hammouti, I.L. Chung, S. Jodeh and H. Lgaz, Metall. Mater. Trans. A, 2018. doi: 10.1007/s11661-018-4828-4

12. T. Ghailane, R.A. Balkhmima, R. Ghailane, A. Souizi, R. Touir, M. Ebn Touhami, K. Marakchi and N. Komiha, Experimental and theoretical studies for mild steel corrosion inhibition in $1 \mathrm{M} \mathrm{HCl}$ by two new benzothiazine derivatives, Corros. Sci., 2013, 76, 317-324. doi: 10.1016/j.corsci.2013.06.052

13. K.F. Khaled, The inhibition of benzimidazole derivatives on corrosion of iron in $1 \mathrm{M}$ $\mathrm{HCl}$ solutions, Electrochim. Acta, 2003, 48, no. 17, 2493-2503. doi: 10.1016/S0013$\underline{\text { 4686(03)00291-3 }}$

14. M. Abdallah, Corrosion behaviour of 304 stainless steel in sulphuric acid solutions and its inhibition by some substituted pyrazolones, Mater. Chem. Phys., 2003, 82, no. 3, 786-792. doi: 10.1016/S0254-0584(03)00367-5

15. M.A. Hegazy, S.M. Rashwan, M.M. Kamel and M.S. El Kotb, Synthesis, surface properties and inhibition behavior of novel cationic gemini surfactant for corrosion of carbon steel tubes in acidic solution, J. Mol. Liq., 2015, 211, 126-134. doi: 10.1016/ j.molliq.2015.06.051

16. D. Ben Hmamou， R. Salghi，A. Zarrouk，H. Zarrok， R. Touzani， B. Hammouti and A. El Assyry, Investigation of corrosion inhibition of carbon steel in $0.5 \mathrm{M} \mathrm{H}_{2} \mathrm{SO}_{4}$ by new bipyrazole derivative using experimental and theoretical approaches, J. Environ. Chem. Eng., 2015, 3, no. 3, 2031-2041. doi: 10.1016/j.jece.2015.03.018

17. E.E. Ebenso, I.B. Obot and L.C. Murulana, Quinoline and its Derivatives as Effective Corrosion Inhibitors for Mild Steel in Acidic Medium, Int. J. Electrochem. Sci., 2010, 5, 1574-1586.

18. Y. Abboud, A. Abourriche, T. Saffaj, M. Berrada, M. Charrouf, A. Bennamara and H. Hannache, A novel azo dye, 8-quinolinol-5-azoantipyrine as corrosion inhibitor for mild steel in acidic media, Desalination, 2009, 237, no. 1-3, 175-189. doi: 10.1016/j.desal.2007.12.031

19. F. Bentiss, M. Traisnel, L. Gengembre and M. Lagrenée, New triazole derivative as inhibitor of the acid corrosion of mild steel: Electrochemical studies, weight loss determination, SEM and XPS, Appl. Surf. Sci., 1999, 152, no. 3, 237-249. doi: 10.1016/S0169-4332(99)00322-0

20. S. El Arrouji, K. Ismaily Alaoui, A. Zerrouki, S. El Kadiri, R. Touzani, Z. Rais, M. Filali Baba, M. Taleb, F. El-Hajjaji, A. Chetouani and A. Aouniti, The influence of some pyrazole derivatives on the corrosion behaviour of mild steel in $1 \mathrm{M} \mathrm{HCl}$ solution, J. Mater. Environ. Sci., 2016, 7, no. 1, 299-309. 
21. S. El Arouji， K. Alaoui Ismaili， A. Zerrouki， S. El Kadiri，Z. Rais， M. Filali Baba, M. Taleb, K.M. Emran, A. Zarrouk and A. Aouiti, Inhibition effects of a new syntheses pyrazole derivative on the corrosion of mild steel in sulfuric acid solution, Der Pharma Chem., 2015, 7, no. 10, 67-76.

22. B. Zerga, A. Attayibat, M. Sfaira, M. Taleb, B. Hammouti, M. Ebn Touhami, S. Radi and Z. Rais, Effect of some tripodal bipyrazolic compounds on C38 steel corrosion in hydrochloric acid solution, J. Appl. Electrochem., 2010, 40, no. 9, 1575-1582. doi: 10.1007/s10800-010-0164-0

23. S.S. Muralidharam, K.L.N. Phani, S. Pitchumani and S. Ravichandran, Polyamino-Benzoquinone Polymers: A New Class of Corrosion Inhibitors for Mild Steel, J. Electrochem. Soc., 1995, 142, no. 5, 1478. doi: 10.1149/1.2048599

24. F. Growcock and R. Jasinski, Time-resolved impedance spectroscopy of mild steel in concentrated hydrochoric acid, J. Electrochem. Soc., 1989, 136, no. 8, 2310. doi: $10.1149 / 1.2097847$

25. M. Faustin, M. Lebrini, F. Robert and C. Roos, Corrosion studies of C38 steel by alkaloids extract of a tropical plant type, Int. J. Electrochem. Sci., 2011, 6, no. 9, 40954113.

26. N.S. Ayati, S. Khandandel, M. Momeni, M.H. Moayed, A.Davoodi and M. Rahimizadeh, Inhibitive effect of synthesized 2-(3-pyridyl)-3,4-dihydro-4quinazolinone as a corrosion inhibitor for mild steel in hydrochloric acid, Mater. Chem. Phys., 2011, 126, no. 3, 873-879. doi: 10.1016/j.matchemphys.2010.12.023

27. H.H. Rahmani, F. El-Hajjaji, A. El Hallaoui, M. Taleb, Z. Rais, M. El Azzouzi, B. Labriti, K. Ismaily Alaoui and B. Hammouti, Experimental, quantum chemical studies of oxazole derivatives as corrosion inhibitors on mild steel in molar hydrochloric acid medium, Int. J. Corros. Scale Inhib., 2018, 7, no. 4, 509-527. doi: 10.17675/2305-6894-2018-7-4-3

28. S.G. Zhang, W. Lei, M.Z. Xia and F.Y. Wang, QSAR study on N-containing corrosion inhibitors: Quantum chemical approach assisted by topological index, J. Mol. Struct.: THEOCHEM, 2005, 732, no. 1-3, 173-182. doi: 10.1016/j.theochem.2005.02.091

29. A. Popova, E. Sokolova, S. Raicheva and M. Christov, AC and DC study of the temperature effect on mild steel corrosion in acid media in the presence of benzimidazole derivatives, Corros. Sci., 2003, 45, no. 1, 33-58. doi: 10.1016/S0010938X(02)00072-0

30. S. Martinez and M. Metikoš-Huković, A nonlinear kinetic model introduced for the corrosion inhibitive properties of some organic inhibitors, J. Appl. Electrochem., 2003, 33, no. 12, 1137-1142. doi: 10.1023/B:JACH.0000003851.82985.5e

31. L. Afia, R. Salghi, E. Bazzi, L. Bazzi, M. Errami, O. Jbara, S.S. Al-Deyab and B. Hammouti, Testing natural compounds: Argania spinosa Kernels extract and cosmetic oil as ecofriendly inhibitors for steel corrosion in $1 \mathrm{M} \mathrm{HCl}$, Int. J. Electrochem. Sci., 2011, 6, no. 11, 5918-5939. 
32. P.S. Desai and R.T. Vashi, Efficiency of xylenol orange as corrosion inhibitor for aluminium in trichloroacetic acid, Indian J. Chem. Technol., 2010, 17, no. 1, 50-55.

33. A. Zarrouk, H. Zarrok, Y. Ramli, M. Bouachrine, B. Hammouti, A. Sahibed-dine and F. Bentiss, Inhibitive properties, adsorption and theoretical study of 3,7-dimethyl-1(prop-2-yn-1-yl)quinoxalin-2(1H)-one as efficient corrosion inhibitor for carbon steel in hydrochloric acid solution, J. Mol. Liq., 2016, 222, 239-252. doi: 10.1016/j.molliq.2016.07.046

34. A. Tazouti, M. Galai, R. Touir, M.E. Touhami, A. Zarrouk, Y. Ramli, M. Saraçoğlu, S. Kaya, F. Kandemirli and C. Kaya, Experimental and theoretical studies for mild steel corrosion inhibition in $1.0 \mathrm{M} \mathrm{HCl}$ by three new quinoxalinone derivatives, $\mathrm{J}$. Mol. Liq., 2016, 221, 815-832. doi: 10.1016/j.molliq.2016.03.083

35. H. Gerengi, K. Darowicki, G. Bereket and P. Slepski, Evaluation of corrosion inhibition of brass-118 in artificial seawater by benzotriazole using Dynamic EIS, Corros. Sci., 2009, 51, no. 11, 2573-2579. doi: 10.1016/j.corsci.2009.06.040

36. I.S. Sanja Martinez, Thermodynamic characterization of metal dissolution and inhibitor adsorption processes in the low carbon steel/mimosa tannin/sulfuric acid system, Appl. Surf. Sci., 2002, 199, 83-89. doi: 10.1016/S0169-4332(02)00546-9

37. J. Cruz, R. Martinez, J. Genesca and E.E. Garc 1a-Ochoa, Experimental and theoretical study of 1-(2-ethylamino)-2-methylimidazoline as an inhibitor of carbon steel corrosion in acid media, J. Electroanal. Chem., 2004, 566, no. 5, 111-121. doi: 10.1016/j.jelechem.2003.11.018

38. M. Elachouri, M.S. Hajji, M. Salem, S. Kertit, J. Aride, R. Coudert and E. Essassi, Some Nonionic Surfactants as Inhibitors of the Corrosion of Iron in Acid Chloride Solutions, Corrosion, 1996, 52, no. 2, 103-108. doi: $10.5006 / 1.3292100$

39. J.R.B. Thavamani, E. Rani and T. Jeyaraj, Inhibition of the corrosion of aluminium in alkaline medium by 1-(phenyl)-3-(2-hydroxy phenyl)-propenone in the presence of tetrabutylammonium bromide, Chem. Sin., 2012, 3, no. 6, 1358-1368.

40. A.K. Singh, S.K. Shukla, M. Singh and M.A. Quraishi, Inhibitive effect of ceftazidime on corrosion of mild steel in hydrochloric acid solution, Mater. Chem. Phys., 2011, 129, no. 1-2, 68-76. doi: 10.1016/j.matchemphys.2011.03.054

41. I.B. Obot, N.O. Obi-egbedi and S. Umoren, Adsorption Characteristics and Corrosion Inhibitive Properties of Clotrimazole for Aluminium Corrosion in Hydrochloric Acid, Int. J. Electrochem. Sci., 2009, 4, 863-877.

42. B.E. Conway and E. Gileadi, Kinetic Theory of Pseudo-Capacitance and Electrode Reactions at Appreciable Surface Coverage, Trans. Faraday Soc., 1962, 58, $2493-$ 2509. doi: 10.1039/TF9625802493

43. E. Ech-chihbi, M.E. Belghiti, R. Salim, H. Oudda, M. Taleb, N. Benchat, B. Hammouti and F. El-Hajjaji, Surf. Interfaces, 2017, 9, 206-217. doi: 10.1016/j.surfin.2017.09.012

44. M. Özcan, R. Solmaz, G. Kardaş and I. Dehri, Adsorption properties of barbiturates as green corrosion inhibitors on mild steel in phosphoric acid, Colloids Surf., A, 2008, 325, no. 1-2, 57-63. doi: 10.1016/j.colsurfa.2008.04.031 
45. C. Küstü, K.C. Emregül and O. Atakol, Schiff bases of increasing complexity as mild steel corrosion inhibitors in $2 \mathrm{M} \mathrm{HCl}$, Corros. Sci., 2007, 49, no. 7, 2800-2814. doi: 10.1016/j.corsci.2007.02.002

46. E.D. Raczyńska, M. Makowski, E. Górnicka and M. Darowska, Ab initio studies on the preferred site of protonation in cytisine in the gas phase and water, Int. J. Mol. Sci., 2005, 6, no. 1-2, 143-156. doi: $\underline{10.3390 / 16010143}$ 